\title{
Article
}

\section{IL13R $\alpha 2$ Is Involved in the Progress of Renal Cell Carcinoma through the JAK2/FOXO3 Pathway}

\author{
Mi-Ae Kang ${ }^{1,+}$, Jongsung Lee ${ }^{2,+} \mathbb{D}$, Chang Min Lee ${ }^{3,+}$, Ho Sung Park $4,5,6 \mathbb{D}$, Kyu Yun Jang $4,5,6, * \mathbb{D}$ \\ and See-Hyoung Park ${ }^{3, *}$ (D)
}

1 Department of Biological Science, Gachon University, Seongnam 13120, Korea; makang53@hanmail.net

2 Department of Integrative Biotechnology, Sungkyunkwan University, Suwon 16419, Korea; bioneer@skku.edu

3 Department of Bio and Chemical Engineering, Hongik University, Sejong 30016, Korea; yycc456@naver.com

4 Department of Pathology, Jeonbuk National University Medical School, Jeonju 54896, Korea; hspark@jbnu.ac.kr

5 Research Institute of Clinical Medicine of Jeonbuk National University, Jeonju 54896, Korea

6 Biomedical Research Institute of Jeonbuk National University Hospital, Jeonju 54896, Korea

* Correspondence: kyjang@jbnu.ac.kr (K.Y.J.); shpark74@hongik.ac.kr (S.-H.P.); Tel.: +82-63-270-3136 (K.Y.J.); +82-44-860-2126 (S.-H.P.)

+ These authors contributed equally to this work.

Citation: Kang, M.-A.; Lee, J.; Lee, C.M.; Park, H.S.; Jang, K.Y.; Park, S.-H. IL13R $\alpha 2$ Is Involved in the Progress of Renal Cell Carcinoma through the JAK2/FOXO3 Pathway. J. Pers. Med. 2021, 11, 284. https:// doi.org/10.3390/jpm11040284

Academic Editor: James Meehan

Received: 22 February 2021

Accepted: 7 April 2021

Published: 8 April 2021

Publisher's Note: MDPI stays neutral with regard to jurisdictional claims in published maps and institutional affiliations.

Copyright: (c) 2021 by the authors. Licensee MDPI, Basel, Switzerland. This article is an open access article distributed under the terms and conditions of the Creative Commons Attribution (CC BY) license (https:// creativecommons.org/licenses/by/ $4.0 /)$.

\begin{abstract}
Previously, we reported a close relationship between type II IL4R $\alpha$ and IL13R $\alpha 1$ complex and poor outcomes in renal cell carcinoma (RCC). In this study, we investigated the clinicopathologically significant oncogenic role of IL13R $\alpha 2$, a kind of the independent receptor for IL13, in 229 RCC patients. The high expression of IL13R $\alpha 2$ was closely related to relapse-free survival in specific cancers in univariate and multivariate analysis. Then, the oncogenic role of IL13R $\alpha 2$ was evaluated by performing in vitro assays for cell proliferation, cell cycle arrest, and apoptosis in A498, ACHN, Caki1, and Caki2, four kinds of RCC cells after transfection of siRNA against IL13R $\alpha 2$. Cell proliferation was suppressed, and apoptosis was induced in A498, ACHN, Caki1, and Caki2 cells by knockdown of IL13R $\alpha 2$. Interestingly, the knockdown of IL13R $\alpha 2$ decreased the phosphorylation of JAK 2 and increased the expression of FOXO3. Furthermore, the knockdown of IL13R $\alpha 2$ reduced the protein interaction among IL13R $\alpha 2$, phosphorylated JAK2, and FOXO3. Since phosphorylation of JAK2 was regulated by IL13R $\alpha 2$, we tried to screen a novel JAK2 inhibitor from the FDA-approved drug library and selected telmisartan, a clinically used medicine against hypertension, as one of the strongest candidates. Telmisartan treatment decreased the cell proliferation rate and increased apoptosis in A498, ACHN, Caki1, and Caki2 cells. Mechanistically, telmisartan treatment decreased the phosphorylation of JAK2 and increased the expression of FOXO3. Taken together, these results suggest that IL13R $\alpha 2$ regulates the progression of RCC via the JAK2/FOXO3-signaling path pathway, which might be targeted as the novel therapeutic option for RCC patients.
\end{abstract}

Keywords: IL13R $\alpha 2$; renal cell carcinoma; JAK2; FOXO3; telmisartan

\section{Introduction}

Every year, there are more than 300,000 new renal cell carcinoma cases (RCC) diagnosis globally [1]. Among them, about $30 \%$ of patients were diagnosed with metastatic RCC [2]. Moreover, the 5-year survival rate of patients with metastatic RCC is lower than $10 \%$ [3]. The prognosis of RCC patients is divided into several categories, such as favorable, intermediate, and poor-risk disease according to well-characterized clinical and laboratory risk factors [4]. Approximately 75\% of patients with RCC have a poor-risk disease, and their prognosis is worse than that with a favorable-risk disease [5,6]. Over the past decade, there have been marked advances in the treatment of metastatic RCC. Sorafenib, sunitinib, bevacizumab, and axitinib are effective inhibitors of vascular endothelial growth factor (VEGF) and its receptor (VEGFR) [7]. Everolimus and temsirolimus inhibited the 
mechanistic target of rapamycin complex 1 (mTORC1) [8]. However, the mortality rate of metastatic RCC is still high because of resistance to conventional chemotherapy and the side effect of radiation therapy [9]. Therefore, we still need to consider the efficient treatment option for RCC.

IL13R $\alpha 2$ is a membrane-bound protein encoded by the IL13R $\alpha 2$ gene [10]. IL13R $\alpha 2$ is closely associated with IL13R $\alpha 1$, a subunit of type II IL4R $\alpha$ and IL13R $\alpha 1$ complex [10]. IL13 binds IL13R $\alpha 2$ with high-affinity [10]. Recently, IL13R $\alpha 2$ has been considered an important target for cancer treatment in various clinical studies [11]. A recent study indicated that IL13R $\alpha 2$ is a potential marker and therapeutic target for human melanoma treatment [12]. It was reported that IL13R $\alpha 2$ was overexpressed in metastatic colorectal cancer and inhibition of IL13 binding to IL13R $\alpha 2$ showed the therapeutic activity in colorectal cancer by reducing metastatic spread [13]. Furthermore, it was demonstrated that targeting IL13R $\alpha 2$ depletion suppressed breast tumor growth and IL13R $\alpha 2$ activated IL13-mediated STAT6-signaling pathway, and knockdown of IL13R $\alpha 2$ suppressed breast cancer metastasis into the lung [14]. Therefore, IL13R $\alpha 2$ could be a potential biomarker to diagnose various cancers. However, there is not enough study for the clinical analysis, biological function, and molecular mechanisms of IL13R $\alpha 2$ in RCC development.

Drug repositioning means the application of the drugs that have been clinically used to other diseases by elucidating the novel activities and target proteins [15]. Since the clinically used drugs were approved by the US Food and Drug Administration (FDA), drug repositioning has many advantages, such as no need to test toxicity and to evaluate pharmacokinetics. Furthermore, there are many previous reports and patents for studying the metabolism and interactions of the old drug, which could help researchers to examine the possible working mechanism of the old drug in the new application. Thus, drug repositioning could considerably save the cost and time for researchers to develop efficient drugs leading to improve the success rate [16]. For the proof-of-concept trial, we successfully selected telmisartan, a clinically used medicine against hypertension, as the strongest JAK2 inhibitor. Telmisartan is known as an agonist of angiotensin II receptor, but not reported on the possible involvement of-signaling pathway, including the regulation of JAK2 [17].

In this study, we investigated the clinical implication and oncogenic role of IL13R $\alpha 2$ in RCC progression. Interestingly, IL13R $\alpha 2$ seemed to increase the phosphorylation of JAK2 and decrease the expression of FOXO3. These results suggest that IL13R $\alpha 2$ regulates RCC progression through JAK2/FOXO3-signaling pathway. Since JAK2 was regulated by IL13R $\alpha 2$ and type II IL4R $\alpha$ and IL13R $\alpha 1$ complex, we tried to screen an FDA-approved drug library with a JAK2 kinase assay kit to identify the novel candidates that were possibly inhibiting JAK2 in RCC cells. Here, we show that telmisartan has the potential for antiproliferative activity in RCC cells, which could broaden the therapeutic options for RCC patients.

\section{Materials and Methods}

\subsection{RCC Patients and Tissue Samples}

RCC patients who operated between July 1998 and August 2011 at Jeonbuk National University Hospital were analyzed in this study. Medical records, histologic and tissue samples were available in 229 cases and included in this study. The clinicopathologic information for patients with RCC was obtained by analyzing medical records and original histologic slides. Tumor stage and histopathologic factors were re-evaluated according to the World Health Organization classification of the renal tumor [18] and the 8th edition of the staging system of the American Joint Committee on Cancer [19]. Histological subtypes of RCCs included in this study were 201 cases of clear cell RCC (CCRCC), 16 cases of chromophobe RCC, and twelve cases of papillary RCC. This study obtained institutional review board approval from Jeonbuk National University Hospital (IRB No., CUH 2019-11039) and was performed according to the Declaration of Helsinki. The approval contained a waiver for written informed consent based on the retrospective and anonymous character of this study. 


\subsection{Immunohistochemical Staining and Scoring}

Immunohistochemical staining in RCC tissue was performed using tissue microarray sections. One $3.0 \mathrm{~mm}$ core per case was arrayed in tissue microarray. The tissue microarray core was obtained from the area of the original paraffin-embedded tissue block, mainly composed of tumor cells with the highest histologic grade. The histologic sections were deparaffinized and boiled with the microwave oven for $20 \mathrm{~min}$ in $\mathrm{pH} 6.0$ antigen retrieval solution (DAKO, Glostrup, Denmark) to induce antigen retrieval. Thereafter, the tissue sections are incubated with anti-IL13R $\alpha 2$ primary antibody (1:100 dilution, Santa Cruz Biotechnology, Santa Cruz, CA, USA) and visualized using the enzyme-substrate 3-amino-9ethylcarbazole. Immunohistochemical staining scoring was performed by two pathologists (HSP and KYJ) with consensus by observing in a multi-viewing microscope. The scoring was performed without clinicopathologic information. The score obtained by adding staining intensity point (point 0 ; no staining, point 1 ; weak, point 2; intermediate, point 3; strong) and staining area point (point 0 ; no staining, point $1 ; 1 \%$, point $2 ; 2-10 \%$, point $3: 11-$ $33 \%$, point $4 ; 34-66 \%$, point $5 ; 67-100 \%$ ) [20-22]. Therefore, the immunohistochemical staining score ranged from zero to eight.

\subsection{Chemical Reagents, Antibodies, and Plasmid DNAs}

The FDA-approved drug library (SCREEN-WELL FDA-approved drug library V2, 821 drugs) was purchased from Enzo Life Sciences (Farmingdale, NY, USA). Mouse anti$\beta$-actin antibody, mouse anti-Myc antibody, mouse anti-HA antibody, protease inhibitors, phosphatase inhibitors, AZD1480, telmisartan, the following chemicals, and solvents (non-fat dry milk powder, dimethyl sulfoxide (DMSO), ethylenediaminetetraacetic acid (EDTA), glycerol, glycine, sodium chloride, Trizma base, Triton X-100, sodium dodecyl sulfate (SDS), crystal violet, $4 \%$ paraformaldehyde solution, 4',6-diamidino-2-phenylindole (DAPI), propidium iodide (PI), and Tween-20) were from Sigma (St. Louis, MO, USA). Control siRNA, siRNA against IL13R $\alpha 2$, protein A or G-agarose beads, rabbit anti-IL13R $\alpha 2$, and rabbit anti-FOXO3 antibodies were purchased from Santa Cruz Biotechnology (Santa Cruz, CA, USA). Rabbit anti-JAK2, rabbit anti-phospho-JAK2 (pJAK2), rabbit anti-cleaved PARP1, rabbit anti-cleaved caspase3, and rabbit anti-p27 antibodies were purchased from Cell Signaling Technology (Danvers, MA, USA). Goat anti-rabbit and goat anti-mouse horseradish peroxidase (HRP)-conjugated IgG (heavy/light or light chain-specific) were from Jackson ImmunoResearch (West Grove, PA, USA). Enhanced chemiluminescence (ECL) reagent was from GE Healthcare (Little Chalfont, United Kingdom). pCMV3-C-HA and pCMV3-JAK2-C-HA plasmid DNA were from Sino Biological (Wayne, PA, USA).

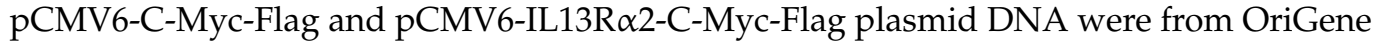
(Rockville, MD, USA).

\subsection{Cell Culture}

A498, ACHN, Caki1, Caki2, and 293T cells were purchased from ATCC (Manassas, VA, USA) and were grown in Dulbecco's modified Eagle's media (DMEM, Invitrogen, Carlsbad, CA, USA) media containing $10 \%$ fetal bovine serum (FBS, Invitrogen) and $1 \%$ streptomycin/penicillin. The cells were cultured in a humidified incubator $(5 \% \mathrm{CO}$, $37^{\circ} \mathrm{C}$ ). We performed all experiments with early passages cells (passages $4-10$ ).

\subsection{Transfection of siRNA and Plasmid DNA}

Cells were plated $\left(5.0 \times 10^{5}\right.$ cells/well) in $60 \mathrm{~mm}$ cell culture dishes and incubated for $18 \mathrm{~h}$ in an incubator. After $18 \mathrm{~h}$ of incubation, cells were transfected with siRNAs (siRNA against IL13R $\alpha 2$ : sc-63339, control siRNA: sc-37007 from Santa Cruz, $1 \mu \mathrm{L}$ ) or plasmid DNAs (pCMV3-C-HA empty/HA-JAK2 plasmid DNA, $1 \mu \mathrm{g}$ ). siRNAs or plasmid DNAs were mixed with $3 \mu \mathrm{L}$ of lipofectamine 2000 (Invitrogen), respectively, in $600 \mu \mathrm{L}$ of serum-free media for $20 \mathrm{~min}$. After PBS washing twice, the cells were incubated with the media containing siRNAs or DNAs for $6 \mathrm{~h}$ in a humidified incubator. After $6 \mathrm{~h}$, cell culture 
media was removed, and fresh media containing 10\% FBS was added. After then, the cells were incubated for $18 \mathrm{~h}$.

\subsection{WST-1 Assay}

Cells were plated $\left(1 \times 10^{3}\right.$ cells/well $)$ in 96-well plates and incubated for $18 \mathrm{~h}$ in a humidified incubator. After incubation, cells were transfected with control/IL13R $\alpha 2$ siRNA or treated with DMSO $(0.1 \%)$ control/the indicated treatment for 24,48 , or $72 \mathrm{~h}$. After incubation, $20 \mu \mathrm{L}$ of EZ-Cytox (DoGenBio, Republic of Korea) was added to the medium. After $4 \mathrm{~h}$, absorbance was measured at $460 \mathrm{~nm}$ wavelength by a microplate reader (Bio-Rad Laboratories, Hercules, CA, USA).

\subsection{Cell Counting Assay}

Cells were plated $\left(2 \times 10^{4}\right.$ cells $/$ well $)$ in $60 \mathrm{~mm}$ culture dishes and incubated for $18 \mathrm{~h}$ in an incubator. After incubation, cells were transfected with control/IL13R $\alpha 2$ siRNA or treated with DMSO (0.1\%) control/the indicated treatment for 14 days. The number of cells was counted by a hemocytometer.

\subsection{Colony Formation Assay}

Cells were plated $\left(5 \times 10^{2}\right.$ cells/well) in $60 \mathrm{~mm}$ culture dishes and incubated for $18 \mathrm{~h}$ in a humidified incubator. After incubation, cells were transfected with control/IL13R $\alpha 2$ siRNA or treated with DMSO $(0.1 \%)$ control/the indicated treatment for 2 weeks. Cells were transfected with IL13R $\alpha 2$ or control siRNA every other day, changing cell culture media. Similarly, Cells were treated with telmisartan or the same volume of DMSO vehicle every other day, changing cell culture media. The cells were fixed with $4 \%$ formaldehyde (Sigma) and stained using 1\% crystal violet (Sigma). The number of colonies was counted.

\subsection{Cell Cycle Analysis}

Cells were plated $\left(5 \times 10^{5}\right.$ cells/well $)$ in $60 \mathrm{~mm}$ cell culture dishes and incubated for $18 \mathrm{~h}$ in a humidified incubator. After incubation, cells were transfected with control/IL13R $\alpha 2$ siRNA or treated with DMSO $(0.1 \%)$ control/the indicated treatment for $48 \mathrm{~h}$. Then, the cells were trypsinized and fixed in $70 \%$ ice-cold absolute ethanol overnight at $-20{ }^{\circ} \mathrm{C}$. After then, centrifugation was carried out (1000 rpm, $5 \mathrm{~min}$ ), and the cells were suspended with propidium iodide (PI) solution for $30 \mathrm{~min}$ at $37^{\circ} \mathrm{C}$. After staining, cell cycle distribution was analyzed by a FACSCalibur (BD Biosciences, San Jose, CA, USA), and the data were analyzed using the FlowJo program (De Novo Software, Glendale, CA, USA).

\subsection{TUNEL Assay}

Cells were plated $\left(5 \times 10^{5}\right.$ cells/well $)$ in $60 \mathrm{~mm}$ cell culture dishes and incubated for $18 \mathrm{~h}$ in a humidified incubator. After incubation, cells were transfected with control/IL13R $\alpha 2$ siRNA or treated with DMSO $(0.1 \%)$ control/the indicated treatment for $48 \mathrm{~h}$. After transfection, the cells were fixed in $4 \%$ formaldehyde solution at $4{ }^{\circ} \mathrm{C}$ for $20 \mathrm{~min}$. After fixation, the cells were permeabilized with $0.2 \%$ Triton X100 (Sigma). DNA strand breaks labeling was performed using a TUNEL assay kit (Promega, Madison, WI, USA). Nuclei were dyed with DAPI.

\subsection{Annexin $V$ Staining Analysis}

Cells were plated $\left(5 \times 10^{5}\right.$ cells/well) in $60 \mathrm{~mm}$ culture dishes and incubated for $18 \mathrm{~h}$ in a humidified incubator. After incubation, cells were transfected with control/IL13R $\alpha 2$ siRNA or treated with DMSO $(0.1 \%)$ control/the indicated treatment for $48 \mathrm{~h}$. The cells were trypsinized and resuspended in annexin V-binding buffer. The percentage of apoptotic cells was evaluated by a FITC annexin V apoptosis detection kit I (BD Biosciences) with PI according to the manufacturer's protocol. $1 \times 10^{4}$ events were collected for each run. Cells were analyzed by a FACSCalibur (BD Biosciences), and FlowJo software (De Novo Software) was used to analyze the data. 


\subsection{Western Blotting Analysis}

Cells were lysed in lysis buffer (RIPA buffer, Cell Signaling Technology, USA) containing protease and phosphatase inhibitors. Centrifugation $\left(10,000 \times g, 4{ }^{\circ} \mathrm{C}, 10 \mathrm{~min}\right)$ was carried out, and protein lysates were separated on 10\% NuPAGE pre-casting gels (Invitrogen) and transferred to nitrocellulose membranes (Bio-Rad Laboratories). The membranes were blocked with $3 \%$ defatted dry milk powder at room temperature for $1 \mathrm{~h}$, and immunoblotting was performed with specific primary antibodies (overnight, $4{ }^{\circ} \mathrm{C}$ ). Membranes were incubated with HRP-conjugated anti-mouse or anti-rabbit IgG in 3\% defatted dry milk powder at room temperature for $1 \mathrm{~h}$. Finally, the bands were detected using ECL solution (GE Healthcare, Chicago, IL, USA) and ChemiDoc system (Bio-Rad Laboratories).

\subsection{Immunoprecipitation Analysis}

Cells were lysed in lysis buffer (RIPA buffer, Cell Signaling Technology) containing protease and phosphatase inhibitors. Centrifugation $\left(10,000 \times g, 4{ }^{\circ} \mathrm{C}, 10 \mathrm{~min}\right)$ was carried out, and protein lysates were separated. The protein lysates were incubated with a specific primary antibody by rotating at $4{ }^{\circ} \mathrm{C}$ overnight. After then, $20 \mu \mathrm{L}$ of $50 \%$ protein A or $\mathrm{G}$-agarose slurry (Santa Cruz) was added to the lysates and rotating for $2 \mathrm{~h}$ at $4{ }^{\circ} \mathrm{C}$. Protein A or G-agaroses containing antigen-antibody complexes were collected and rinsed with PBS. Immunoprecipitants were analyzed by Western blotting.

\subsection{JAK2 Kinase Inhibition Assay}

Inhibitory activity of AZD1480 and telmisartan against JAK2 was evaluated by JAK2 kinase assay kit (BPS Bioscience, San Diego, CA, USA) and Glo-Max kinase assay kit (Promega). Briefly, according to the manufacturer's instructions, recombinant JAK2 protein was incubated with the indicated concentration of AZD1480 or telmisartan, peptide substrate, and ATP for $30 \mathrm{~min}$ at $37^{\circ} \mathrm{C}$. After incubation, the reaction mixture was incubated with Glo-Max solution for $30 \mathrm{~min}$ at room temperature to stop the reaction. Then, the remaining ATP level in each reaction was measured by a microplate reader for luminescence (Bio-Rad Laboratories).

\subsection{Statistical Analysis}

The immunohistochemical staining score for IL13R $\alpha 2$ in the RCC tissue sample was grouped into negative and positive cases with receiver operating characteristic curve analysis [22-24]. The cutoff point for IL13R $\alpha 2$ immunostaining score to discriminate negative or positive cases was determined at the point that significantly estimates patients' death from RCC. The cutoff point has the highest area under the curve in the receiver operating characteristic curve analysis. The survival analysis was conducted for cancer-specific survival (CSS) and relapse-free survival (RFS) through December 2013. The duration for CSS was calculated from the date of diagnosis to the date of the patient's last contact or death. The event in CSS analysis was the death of patients from RCC. The death of patients from other causes or alive of patients finally contact was censored in CSS analysis. The duration for RFS was calculated from the date of diagnosis to the date of the last contact without relapse, the date of the first relapse, or patients' death. The event in RFS analysis was a relapse of RCC or death of patients from RCC. Patients' death from other causes or alive of patients finally contact without relapse were censored in RFS analysis. The survival analysis was performed with univariate and multivariate Cox proportional hazards regression analyses and Kaplan-Meier survival analysis using SPSS software (version 20.0, IBM, CA, USA). The association between clinicopathological factors was analyzed by Pearson's chi-squared test using SPSS software, and all statistical tests were two-sided. The values of $P$ lower than 0.05 were considered statistically significant. 


\section{Results \\ 3.1. Immunohistochemical Expression of IL13R $\alpha 2$ Is Associated with Poor Prognosis of RCC Patients}

The immunohistochemical staining for IL13R $\alpha 2$ was seen in tumor cells of all histologic subtypes of RCC (Figure 1A). The cut-off point for IL13R $\alpha 2$ immunostaining was seven in receiver operating characteristic curve analysis (Figure 1B). The cases have immunohistochemical staining scores equal to, or greater than, seven were grouped as positive for IL13R $\alpha 2$ staining. In this cut-off value, IL13R $\alpha 2$-positivity was significantly associated with tumor size $(P=0.004)$, tumor stage $(P=0.002)$, histologic nuclear grade of tumor cells $(P<0.001)$, and histologic subtype of RCC $(P=0.005)$ in 229 cases of RCCs (Table 1$)$. CCRCC is the major histologic subtype of RCC, and there were 201 cases of CCRCC in this study. Therefore, we also evaluated in CCRCC subgroup of RCCs. In CCRCC subgroup, IL13R $\alpha 2$-positivity was significantly associated with tumor size $(P=0.005)$, tumor stage $(P=0.003)$, and histologic nuclear grade of tumor cells $(P<0.001)$ (Table 1$)$. In 229 overall RCCs, the factors significantly associated with CCS or RFS in univariate analysis were age (CSS, $P<0.001$; RFS, $P=0.005$ ), tumor size (CSS, $P<0.001$; RFS, $P<0.001$ ), tumor stage (CSS, $P<0.001$; RFS, $P<0.001)$, lymph node metastasis (CSS, $P=0.615$; RFS, $P<0.001$ ), histologic nuclear grade (CSS, overall $P=0.032$; RFS, overall $P=0.008$ ), tumor necrosis (CSS, $P<0.001$; RFS, $P=0.004)$, and IL13R $\alpha 2$-positivity (CSS, $P=0.002$; RFS, $P<0.001$ ) (Table 2$)$. The IL13R $\alpha 2-$ positivity showed a 3.726-fold (95\% confidence interval [95\% CI]; 1.636-8.489, $P=0.002)$ greater risk of death and a 3.625-fold (95\% CI; 1.806-7.278, $P<0.001)$ greater risk of relapse or death of RCC patients (Table 2). The Kaplan-Meier survival curves for CSS and RFS according to IL13R $\alpha 2$-positivity in overall RCC are presented in Figure 1C. In 201 CCRCCs, the factors significantly associated with CCS or RFS in univariate analysis were age (CSS, $P=0.004$; RFS, $P=0.012$ ), tumor size (CSS, $P<0.001$; RFS, $P<0.001$ ), tumor stage (CSS, $P<0.001$; RFS, $P<0.001$ ), lymph node metastasis (CSS, $P=0.721$; RFS, $P=0.011$ ), histologic nuclear grade (CSS, overall $P=0.170$; RFS, overall $P=0.028$ ), tumor necrosis (CSS, $P=0.005$; RFS, $P=0.063$ ), and IL13R $\alpha 2$-positivity (CSS, $P=0.003$; RFS, $P<0.001$ ) (Table 2). The IL13R $\alpha 2$-positivity had a 3.591-fold (95\% CI; 1.546-8.342, $P=0.003)$ greater risk of death from CCRCC and a 3.518-fold (95\% CI; 1.724-7.181, $P<0.001)$ greater risk of relapse or death from CCRCC (Table 2). The Kaplan-Meier survival analysis also showed significant prognostic significance of IL13R $\alpha 2$ expression for CSS and RFS in CCRCC subgroups (Figure 2A). However, in chromophobe RCC and papillary RCC, despite relatively shorter survival of IL13R $\alpha 2$-positive subgroups compared with IL13R $\alpha 2$ negative subgroups, there was no significant difference in survival of patients (Figure 2B,C). Multivariate analysis was performed with the factors significantly associated with CSS or RFS in univariate analysis. The factors included in multivariate analysis were age, tumor size, tumor stage, lymph node metastasis, histologic nuclear grade, tumor necrosis, and immunohistochemical expression of IL13R $\alpha 2$. In 272 overall RCCs, age (CSS, $P=0.018)$, tumor stage (CSS, $P=0.005$; RFS, $P<0.001)$, tumor necrosis (CSS, $P=0.005$; RFS, $P=0.015)$, and IL13R $\alpha 2$ expression (CSS, $P=0.025$; RFS, $P=0.004$ ) were significantly associated with CSS or RFS (Table 3). The IL13R $\alpha 2$-positivity had a 2.627-fold (95\% CI; 1.132-6.097) greater risk of death and a 2.801 -fold $(95 \% \mathrm{CI} ; 1.3795 .688)$ greater risk of relapse or death of RCC patients (Table 3). In 201 CCRCCs, age (CSS, $P=0.042)$, tumor stage (CSS, $P=0.010$; RFS, $P<0.001$ ), tumor necrosis (CSS, $P=0.006$; RFS, $P=0.054$ ), and IL13R $\alpha 2$ expression (CSS, $P=0.019$; RFS, $P=0.005$ ) were significantly associated with CSS or RFS (Table 3 ). The IL13R $\alpha 2$-positivity showed a 2.792-fold (95\% CI; 1.182-6.595) greater risk of death and a 2.838-fold (95\% CI; 1.372-5.870, $P<0.001$ ) greater risk of relapse or death of CCRCC patients (Table 3). Taken together, we investigated the clinicopathologically significant oncogenic role of IL13R $\alpha 2$ in 229 RCC patients and the high expression of IL13R $\alpha 2$ was significantly associated with cancer-specific survival and relapse-free survival in univariate and multivariate analysis. 
Table 1. Clinicopathologic variables and the expression status of IL13R $\alpha 2$ in renal cell carcinomas.

\begin{tabular}{|c|c|c|c|c|c|c|c|}
\hline \multicolumn{2}{|c|}{ Characteristics } & \multicolumn{3}{|c|}{ Overall Renal Cell Carcinoma $(n=229)$} & \multicolumn{3}{|c|}{ Clear Cell Renal Cell Carcinoma $(n=201)$} \\
\hline & & No. & $\begin{array}{l}\text { IL13R } \alpha 2 \\
\text { Positive }\end{array}$ & $P$ & No. & $\begin{array}{l}\text { IL13R } \alpha 2 \\
\text { Positive }\end{array}$ & $P$ \\
\hline \multirow[t]{2}{*}{ Sex } & Male & 156 & $86(55 \%)$ & 0.411 & 140 & $71(51 \%)$ & 0.530 \\
\hline & Female & 73 & $36(49 \%)$ & & 61 & $28(46 \%)$ & \\
\hline \multirow{2}{*}{ Age, y } & $\leq 55$ & 95 & $46(48 \%)$ & 0.215 & 82 & $35(43 \%)$ & 0.122 \\
\hline & $>55$ & 134 & $76(57 \%)$ & & 119 & $64(54 \%)$ & \\
\hline \multirow[t]{2}{*}{ Tumor size, $\mathrm{cm}$} & $\leq 7$ & 193 & $95(49 \%)$ & 0.004 & 169 & $76(45 \%)$ & 0.005 \\
\hline & $>7$ & 36 & $27(75 \%)$ & & 32 & $23(72 \%)$ & \\
\hline \multirow[t]{2}{*}{ TNM stage } & I & 183 & $88(48 \%)$ & 0.002 & 163 & $72(44 \%)$ & 0.003 \\
\hline & II-IV & 46 & $34(74 \%)$ & & 38 & $27(71 \%)$ & \\
\hline \multirow[t]{2}{*}{ LN metastasis } & Absence & 226 & $119(53 \%)$ & 0.103 & 199 & 97 (49\%) & 0.149 \\
\hline & Presence & 3 & $3(100 \%)$ & & 2 & $2(100 \%)$ & \\
\hline \multirow[t]{3}{*}{ Nuclear grade } & 1 & 45 & $17(38 \%)$ & $<0.001$ & 36 & $10(28 \%)$ & $<0.001$ \\
\hline & 2 & 134 & $67(50 \%)$ & & 123 & $59(48 \%)$ & \\
\hline & 3 and 4 & 50 & $38(76 \%)$ & & 42 & $30(71 \%)$ & \\
\hline \multirow[t]{2}{*}{ Necrosis } & Absence & 196 & $102(52 \%)$ & 0.362 & 174 & $85(49 \%)$ & 0.772 \\
\hline & Presence & 33 & $20(61 \%)$ & & 27 & $14(52 \%)$ & \\
\hline \multirow[t]{3}{*}{ Histologic type } & Clear cell & 201 & $99(49 \%)$ & 0.005 & & & \\
\hline & Chromophobe & 16 & $13(81 \%)$ & & & & \\
\hline & Papillary & 12 & $10(83 \%)$ & & & & \\
\hline
\end{tabular}

Table 2. Univariate Cox regression analysis of cancer-specific survival and relapse-free survival in renal cell carcinoma patients.

\begin{tabular}{|c|c|c|c|c|c|}
\hline \multirow[t]{2}{*}{ Characteristics. } & \multirow[t]{2}{*}{ No. } & \multirow{2}{*}{$\begin{array}{c}\text { CSS } \\
\text { HR }(95 \% \text { CI })\end{array}$} & \multicolumn{3}{|c|}{ RFS } \\
\hline & & & $P$ & $\operatorname{HR}(95 \% \mathrm{CI})$ & $P$ \\
\hline \multicolumn{6}{|l|}{ Overall RCC $(n=229)$} \\
\hline Sex, male (vs. female) & $156 / 229$ & $0.564(0.258-1.234)$ & 0.152 & $0.513(0.255-1.030)$ & 0.060 \\
\hline Age, $y,>55($ vs. $\leq 55)$ & $134 / 229$ & $4.386(1.828-10.524)$ & $<0.001$ & $2.537(1.319-4.880)$ & 0.005 \\
\hline Tumor size, $>7 \mathrm{~cm}(\mathrm{vs} . \leq 7 \mathrm{~cm})$ & $36 / 229$ & $3.415(1.736-6.715)$ & $<0.001$ & $3.984(2.218-7.155)$ & $<0.001$ \\
\hline TNM stage, I (vs. II-IV) & $46 / 229$ & $4.231(2.219-8.068)$ & $<0.001$ & $5.166(2.930-9.018)$ & $<0.001$ \\
\hline LN metastasis, presence (vs. absence) & $3 / 229$ & $1.670(0.226-12.308)$ & 0.615 & $17.410(3.874-78.249)$ & $<0.001$ \\
\hline Nuclear grade, 1 & $45 / 229$ & 1 & 0.032 & 1 & 0.008 \\
\hline 2 & $134 / 229$ & $0.943(0.347-2.564)$ & 0.909 & $1.172(0.476-2.883)$ & 0.730 \\
\hline 3 and 4 & $50 / 229$ & $2.327(0.836-6.476)$ & 0.106 & $2.846(1.128-7.179)$ & 0.027 \\
\hline Necrosis, presence (vs. absence) & $33 / 229$ & $3.620(1.842-7.114)$ & $<0.001$ & $2.542(1.345-4.807)$ & 0.004 \\
\hline Histologic type, clear cell & $201 / 229$ & 1 & 0.654 & 1 & 0.328 \\
\hline chromophobe & $16 / 229$ & $0.808(0.193-3.382)$ & 0.771 & $0.585(0.141-2.421)$ & 0.460 \\
\hline papillary & $12 / 229$ & $1.570(0.553-4.462)$ & 0.397 & $1.802(0.711-4.565)$ & 0.214 \\
\hline IL13R $\alpha 2$, positive (vs. negative) & $122 / 229$ & $3.726(1.636-8.489)$ & 0.002 & $3.625(1.806-7.278)$ & $<0.001$ \\
\hline \multicolumn{6}{|l|}{ Clear cell RCC $(n=201)$} \\
\hline Sex, male (vs. female) & $140 / 201$ & $0.541(0.222-1.319)$ & 0.177 & $0.523(0.241-1.132)$ & 0.100 \\
\hline Age, $y,>55($ vs. $\leq 55)$ & $119 / 201$ & $4.152(1.593-10.822)$ & 0.004 & $2.491(1.220-5.084)$ & 0.012 \\
\hline Tumor size, $>7 \mathrm{~cm}($ vs. $\leq 7 \mathrm{~cm})$ & $32 / 201$ & $3.977(1.928-8.204)$ & $<0.001$ & $4.773(2.560-8.900)$ & $<0.001$ \\
\hline TNM stage, I (vs. II-IV) & $38 / 201$ & $3.964(1.953-8.049)$ & $<0.001$ & $5.199(2.814-9.604)$ & $<0.001$ \\
\hline LN metastasis, presence (vs. absence) & $2 / 201$ & $0.049\left(0.000-7.516 \times 10^{5}\right)$ & 0.721 & $14.681(1.841-117.039)$ & 0.011 \\
\hline Nuclear grade, 1 & $36 / 201$ & 1 & 0.170 & 1 & 0.028 \\
\hline 2 & $123 / 201$ & $1.028(0.344-3.075)$ & 0.961 & $1.122(0.423-2.978)$ & 0.817 \\
\hline 3 and 4 & $42 / 201$ & $2.111(0.661-6.739)$ & 0.207 & $2.655(0.955-7.380)$ & 0.061 \\
\hline Necrosis, presence (vs. absence) & $27 / 201$ & $3.044(1.401-6.617)$ & 0.005 & $2.016(0.962-4.225)$ & 0.063 \\
\hline IL13R $\alpha 2$, positive (vs. negative) & $99 / 201$ & $3.591(1.546-8.342)$ & 0.003 & $3.518(1.724-7.181)$ & $<0.001$ \\
\hline
\end{tabular}

Abbreviations: CSS, cancer-specific survival; RFS, relapse-free survival; HR, hazard ratio; 95\% CI, 95\% confidence interval; RCC, renal cell carcinoma; LN, lymph node. 
Table 3. Multivariate Cox regression analysis of cancer-specific survival and relapse-free survival in renal cell carcinoma patients.

\begin{tabular}{|c|c|c|c|c|}
\hline \multirow[t]{2}{*}{ Characteristics } & \multirow{2}{*}{$\begin{array}{c}\text { CSS } \\
\text { HR }(95 \% \text { CI })\end{array}$} & \multicolumn{3}{|c|}{ RFS } \\
\hline & & $P$ & HR (95\% CI) & $P$ \\
\hline \multicolumn{5}{|l|}{ Overall RCC $(n=229) *$} \\
\hline Age, $y,>55$ (vs. $\leq 55)$ & $2.941(1.200-7.209)$ & 0.018 & & \\
\hline TNM stage, I (vs. II-IV) & $2.600(1.331-5.077)$ & 0.005 & $4.036(2.260-7.209)$ & $<0.001$ \\
\hline Necrosis, presence (vs. absence) & $2.686(1.350-5.345)$ & 0.005 & $2.240(1.172-4.278)$ & 0.015 \\
\hline IL13R $\alpha 2$, positive (vs. negative) & $2.627(1.132-6.097)$ & 0.025 & $2.801(1.379-5.688)$ & 0.004 \\
\hline \multicolumn{5}{|l|}{ Clear cell RCC $(n=201)^{* *}$} \\
\hline Age, $y,>55$ (vs. $\leq 55)$ & $2.779(1.036-7.453)$ & 0.042 & & \\
\hline TNM stage, I (vs. II-IV) & $2.616(1.255-5.451)$ & 0.010 & $4.214(2.257-7.867)$ & $<0.001$ \\
\hline Necrosis, presence (vs. absence) & $3.002(1.361-6.618)$ & 0.006 & $2.088(0.988-4.414)$ & 0.054 \\
\hline IL13R $\alpha 2$, positive (vs. negative) & $2.792(1.182-6.595)$ & 0.019 & $2.838(1.372-5.870)$ & 0.005 \\
\hline
\end{tabular}

Abbreviations: CSS, cancer-specific survival; RFS, relapse-free survival; HR, hazard ratio; 95\% CI, 95\% confidence interval; RCC, renal cell carcinoma. * The variables included in the multivariate analysis were age, tumor size, tumor stage, histologic nuclear grade, tumor necrosis, and the expression of IL13R $\alpha 2 .{ }^{* *}$ The variables included in the multivariate analysis were age, tumor size, tumor stage, histologic nuclear grade, tumor necrosis, and the expression of IL13R $\alpha 2$.

A

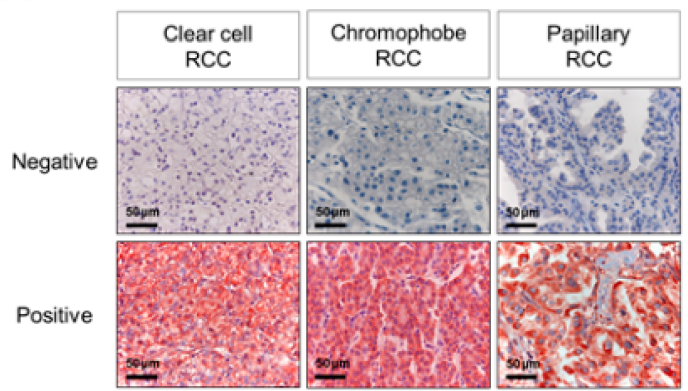

B

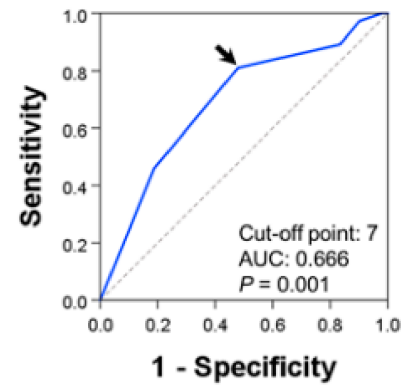

C
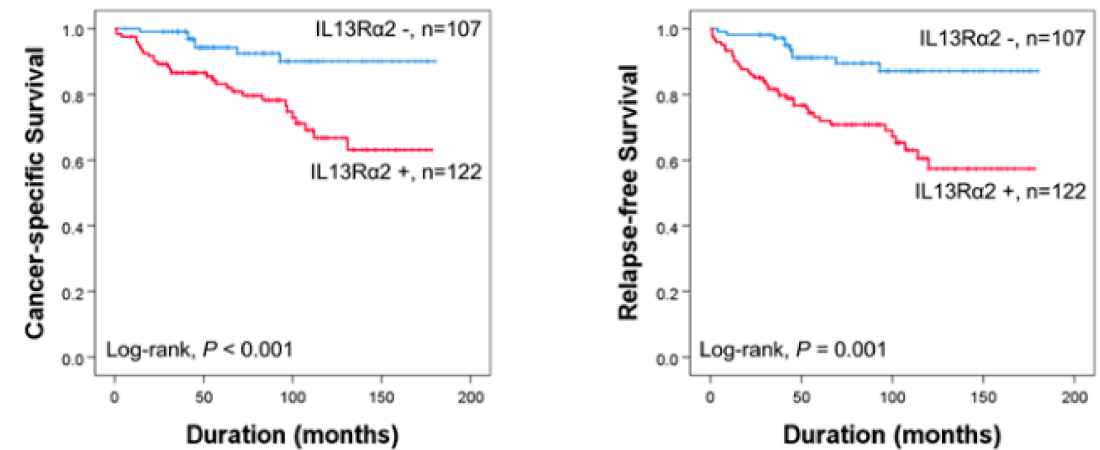

Figure 1. Immunohistochemical expression and survival analysis for the expression of IL13R $\alpha 2$ in renal cell carcinomas. (A) Immunohistochemical expression of IL13R $\alpha 2$ in clear cell renal cell carcinoma, chromophobe renal cell carcinoma, and papillary renal cell carcinoma tissue. Original magnification, $\times 400$. (B) Receiver operator characteristic curve analysis to determine the cutoff point of IL13R $\alpha 2$ immunostaining. The cutoff point is determined to predict cancer-specific survival of renal cell carcinoma patients. The cutoff point has the highest area under the curve (AUC). Arrow indicates a cutoff point for the IL13R $\alpha 2$ immunostaining. (C) Kaplan-Meier survival analysis for cancer-specific survival and relapse-free survival according to the immunohistochemical positivity for IL13R $\alpha 2$ in 229 cell renal cell carcinomas. 
A

Clear cell renal cell carcinoma $(n=201)$
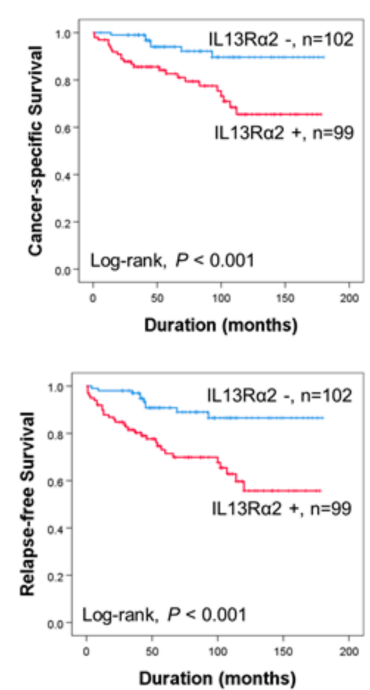

B

Chromophobe renal cell carcinoma $(n=14)$
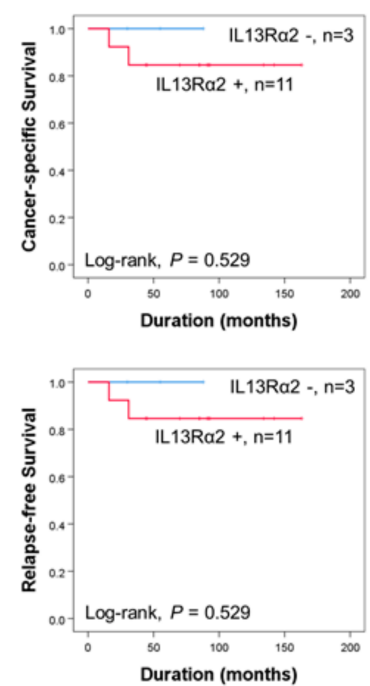

C

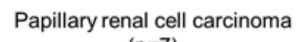

$(n=7)$
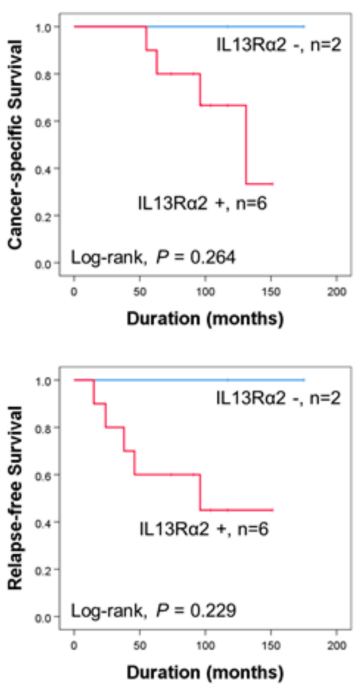

Figure 2. Kaplan-Meier survival analysis in histologic subtypes of renal cell carcinomas. KaplanMeier survival curves for cancer-specific survival (CSS) and relapse-free survival (RFS) according to the expression of IL13R $\alpha 2$ in clear cell renal cell carcinoma (A), chromophobe renal cell carcinoma (B), and papillary renal cell carcinoma $(\mathbf{C})$.

3.2. Knockdown of IL13R 2 Displays the AntiProliferative Activity in A498, ACHN, Caki1, and Caki2 Cells

In 229 cases of human RCC, a significant association between the expression IL13R $\alpha 2$ and poor prognosis was observed by tissue microarray. Hence, as the next step, we tried to investigate the possible oncogenic role of IL13R $\alpha 2$ by performing in vitro assays for cell proliferation, cell cycle arrest, and apoptosis in RCC cells after transfection of siRNA against IL13R $\alpha 2$. WST-1 and cell counting assay were conducted to evaluate the antiproliferative activity of the knockdown of IL13R $\alpha 2$. Cells were transfected with control or siRNA against IL13R $\alpha 2$ and incubated for the indicated time. As shown in Figure 3A,B, compared to the control, cells transfected with siRNA against IL13R $\alpha 2$ showed a decreased proliferation rate, which was confirmed by performing colony formation assay (Figure 3C). Cell cycle analysis showed that knockdown of IL13R $\alpha 2$ with siRNA increased G2/M population in A498, ACHN, Caki1, and Caki2 cells compared to control siRNA (Figure 3D). TUNEL and annexin $\mathrm{V}$ staining assay results showed that knockdown of IL13R $\alpha 2$ with siRNA increased the apoptosis in A498, ACHN Caki1, and Caki2 cells compared to control siRNA (Figure 3E,F). Western blotting analysis indicated that knockdown of IL13R $\alpha 2$ with siRNA increased the expression of cleaved PARP1, cleaved caspase3, FOXO3, and p27 (Figure 3G). Overall, these results indicate that knockdown of IL13R $\alpha 2$ with siRNA transfection could regulate proliferation, cell cycle arrest, and apoptosis in A498, ACHN, Cak1, and Caki2 RCC cells. 

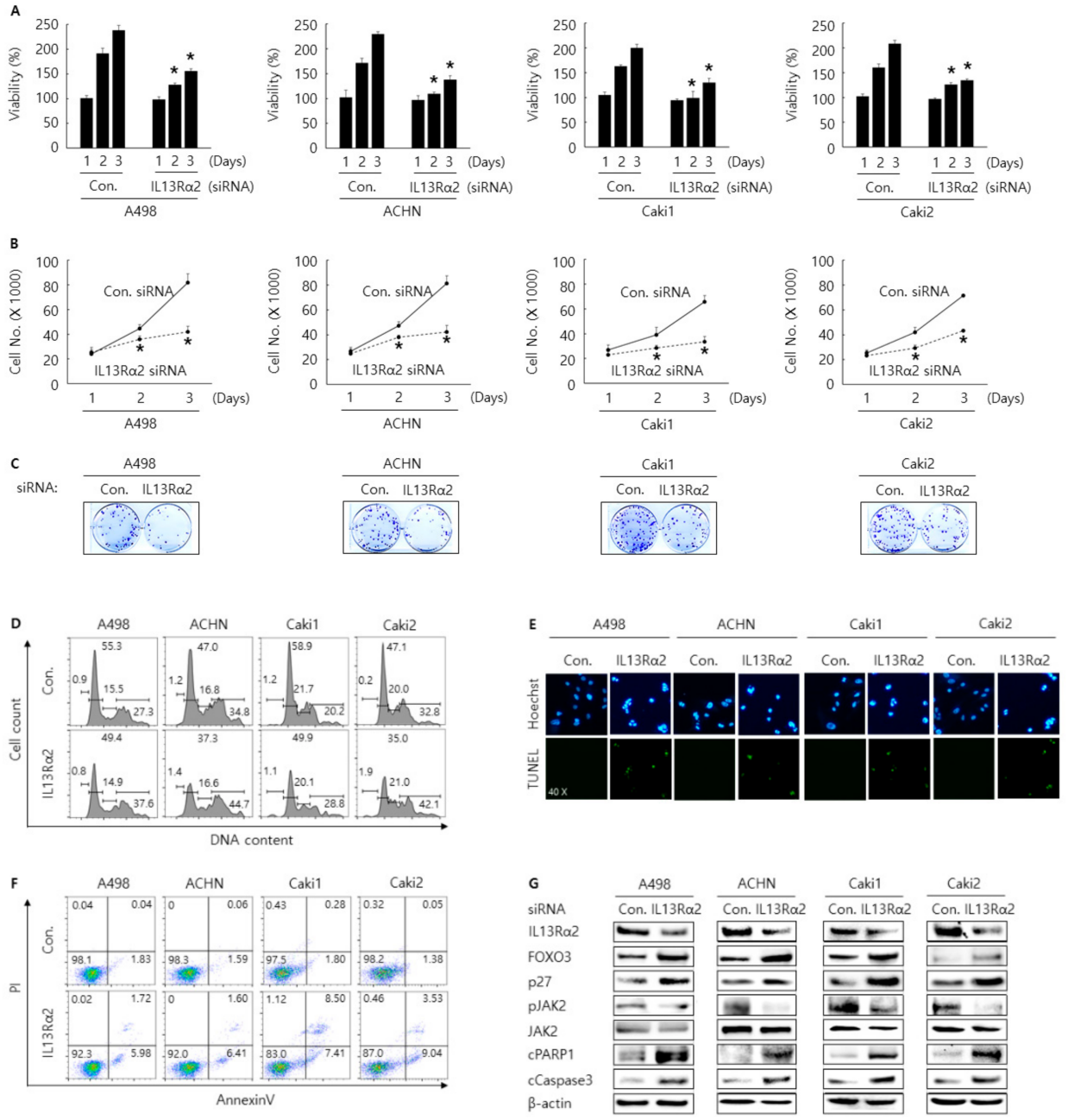

Figure 3. Antiproliferative effect by transfection of siRNA against IL13R $\alpha 2$ in A498, ACHN, Caki1, and Caki2 cells. Cell viability and proliferation rate were determined by WST-1 (A), cell counting assay (B) for 24, 48, and $72 \mathrm{~h}$, and Colony formation assay for 14 days (C). This result is representative data of at least three independent experiments, and the error bar indicates mean \pm standard error (STE). * stands for the $P$-value $<0.05$. Cell cycle arrest for $48 \mathrm{~h}$ after transfection was determined by cell cycle analysis (D). Apoptosis for $48 \mathrm{~h}$ after transfection was determined by Annexin V staining analysis (E) and Terminal deoxynucleotidyl transferase dUTP nick end labeling (TUNEL) assay $(\mathbf{F})$. This result represents at least three independent experiments $(\mathbf{G})$ Western blotting analysis of proteins related to cell cycle arrest and apoptosis for $48 \mathrm{~h}$ after transfection. $\beta$-actin was used for a gel-loading control.

3.3. Knockdown of IL13R $\alpha 2$ Attenuates the Protein Interaction Among IL13R $\alpha 2, p J A K 2$, and FOXO3 in A498, ACHN, Caki1, and Caki2 Cells

In the previous report, we found that pJAK2 interacts with FOXO3, which was regulated by type II IL4R and IL13R $\alpha 1$ heterodimeric receptor complex [21]. Since IL13R $\alpha 2$ can accept IL13 as the same ligand with type II IL4R and IL13R $\alpha 1$ complex, we examined whether the phosphorylation level of JAK2 was regulated by knockdown of siRNA against IL13R $\alpha 2$ in RCC cells. When A498, ACHN, Caki1, Caki2, and 293T cell lysates were analyzed by Western blotting for IL13R $\alpha 2$, pJAK2, JAK2, and FOXO3, there seemed the correlation pattern between IL13R $\alpha 2$ and pJAK2 except for Caki2 cell lysates (Supplementary Figure S1A). In contrast, the expression of pJAK2 and FOXO3 was reversely correlated. In addition, as shown in Figure $3 \mathrm{G}$, the expression of pJAK2 was significantly downregulated by transfection of IL13R $\alpha 2$ with siRNA in A498, ACHN Caki1, and Caki2 cells compared to control siRNA. Then, to investigate the protein interaction among IL13R $\alpha 2$, 
pJAK2, and FOXO3, we performed co-immunoprecipitation experiments with an antibody against IL13R $\alpha 2$, JAK2, and FOXO3 followed by immunoblot analysis with an antibody against IL13R $\alpha 2$, pJAK2, JAK2, and FOXO3 in A498, ACHN Caki1, and Caki2 cells transfected with siRNA against IL13R $\alpha 2$. As shown in Figure $4 \mathrm{~A}-\mathrm{C}$, the protein interaction among IL13R $\alpha 2$, pJAK2 and FOXO3 was weakened in RCC cells transfected with siRNA against IL13R $\alpha 2$ compared to the control siRNA. Furthermore, we could observe that the level of protein interaction between IL13R $\alpha 2$ and JAK2 was increased in 293T cells co-transfected with overexpression plasmid DNA for IL13R $\alpha 2$ or JAK2 (Figure 3D). Collectively, these results implicate that IL13R $\alpha 2$ interacts with JAK2, which may regulate the protein expression level of FOXO3.

A

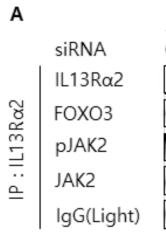

B
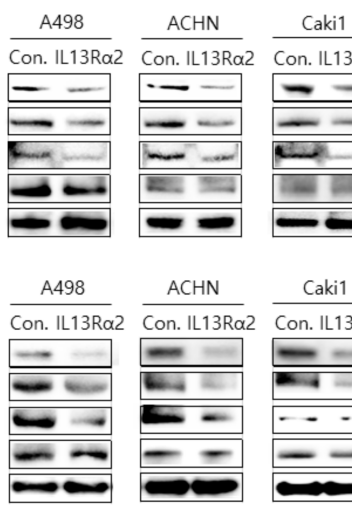

C

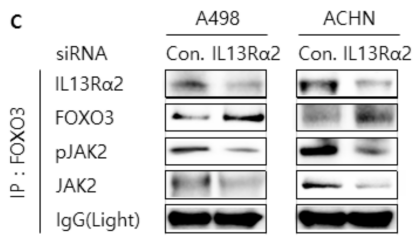

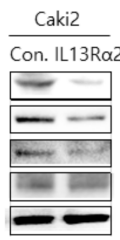
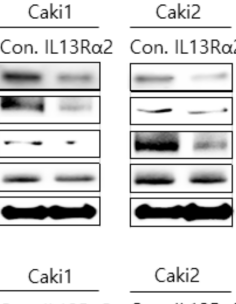
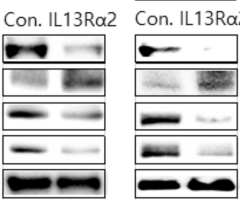

D
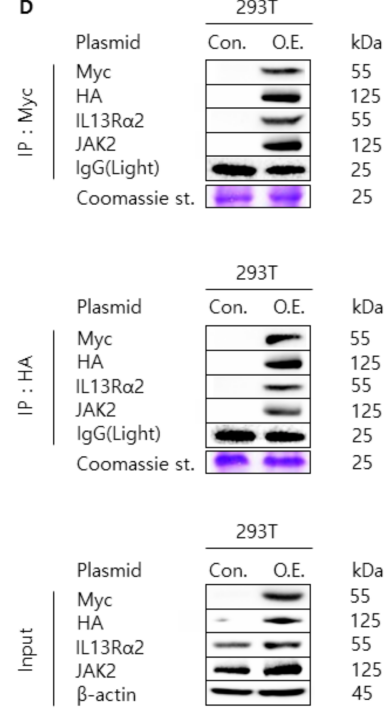

Figure 4. Protein interaction between IL13R $\alpha 2$ and JAK2. Knock-down of IL4R $\alpha 2$ in A498, ACHN, Caki1, and Caki2 cells reduced the interaction between IL13R $\alpha 2$ and JAK2. Cells were transfected with siRNA against IL4R $\alpha 2$ or control siRNA. Then cell lysates were immunoprecipitated with antibodies against IL4R $\alpha 2$ (A), JAK2 (B), or FOXO3 (C). The immunoprecipitated proteins were immunoblotted by IL4R $\alpha 2$, pJAK2, JAK2, and FOXO3 antibodies. Light chain of IgG was used for the loading control. (D) 293T cells were co-transfected with Myc-IL4R $\alpha 2$ and HA-JAK2 (O.E.) or a control plasmid DNA (pCMV6-C-Myc-Flag and pCMV3-C-HA, Con.) as indicated. Then cell lysates were immunoprecipitated with antibodies against Myc or HA. The immunoprecipitated proteins were immunoblotted by Myc, HA, IL4R $\alpha 2$, JAK2 antibodies. Light chain of IgG and Coomassie Blue staining of SDS-PAGE were used for the loading control.

3.4. Telmisartan Suppresses Cell Proliferation and Induces Apoptosis and Cell Cycle Arrest in A498, ACHN, Caki1, and Caki2 Cells Via Inhibition of JAK2

Previously, we reported that type II IL4R $\alpha$ and IL13R $\alpha 1$ complex are involved in RCC progress through regulation JAK2/FOXO3 pathway [21]. In addition, in this study, we showed that JAK2 was regulated by IL13R $\alpha 2$. Thus, we thought that JAK2 was the common downstream-signaling kinase under the type II IL4R $\alpha$ and IL13R $\alpha 1$ complex and IL13R $\alpha 2$. Hence, we tried to find the novel chemical inhibitor against JAK2 as the therapeutic way to treat RCC by screening an FDA-approved drug library (821 drugs) with a JAK2 kinase assay kit. After narrowing down the possible candidates, telmisartan, a clinically used medicine against hypertension, could be selected as one of the strongest JAK2 inhibitors from 821 drugs. As shown in Supplementary Figure S1B, telmisartan reduced ATP consumption in a dose-dependent manner in vitro. In fact, telmisartan treatment decreased the phosphorylation level of JAK2 in A498, ACHN, and 293T transfected with JAK2 overexpression plasmid DNA (Supplementary Figure S1C). To determine the 
anti-carcinogenic effect of telmisartan, we conducted in vitro assays for cell proliferation, cell cycle arrest, and apoptosis in RCC cells after telmisartan treatment. Cells were treated with 0,20 , and $40 \mu \mathrm{M}$ of telmisartan and incubated for the indicated time. As shown in Figure $5 \mathrm{~A}-\mathrm{C}$, telmisartan treatment decreased cell proliferation rate in a dose and timedependent manner. We found that telmisartan treatment increased the G2/M population in A498, ACHN, Caki1, and Caki2 cells compared to DMSO control (Figure 5D). TUNEL and annexin $\mathrm{V}$ staining assay results showed that telmisartan treatment increased the apoptosis in A498, ACHN Caki1, and Caki2 cells compared to DMSO control (Figure 5E,F). Western blotting analysis indicated that telmisartan increased the expression of cleaved PARP1, cleaved caspase3, FOXO3, and p27, whereas decreased the expression of IL13R $\alpha 2$ and pJAK2 (Figure 5G). Overall, these results indicate that telmisartan treatment could regulate proliferation, cell cycle arrest, and apoptosis in A498, ACHN, Cak1, and Caki2 RCC cells via inhibition of JAK2.
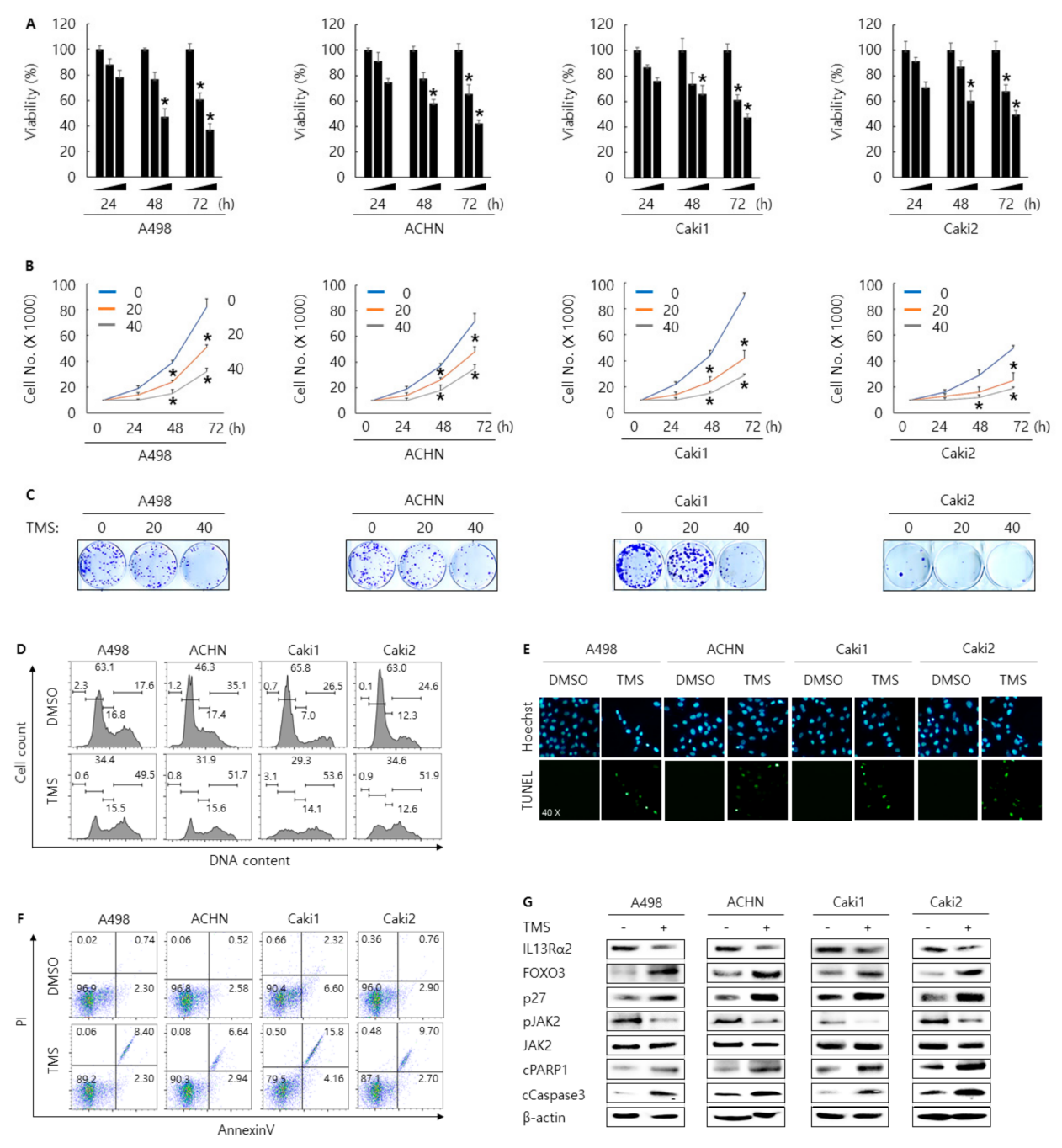

Figure 5. Antiproliferative effect by telmisartan treatment in A498, ACHN, Caki1, and Caki2 cells. Cell viability and proliferation rate were determined by WST-1 (A), cell counting assay (B) for 24, 48, and $72 \mathrm{~h}$, and Colony formation assay for 14 days $(\mathbf{C})$ after treatment of telmisartan $(0,20$, and $40 \mu \mathrm{M})$. This result is representative data of at least three independent experiments, and the error bar indicates mean \pm standard error (STE). * stands for the $P$-value $<0.05$. Cell cycle arrest for $48 \mathrm{~h}$ after treatment of telmisartan $(40 \mu \mathrm{M})$ was determined by cell cycle analysis (D). Apoptosis for $48 \mathrm{~h}$ after treatment of telmisartan $(40 \mu \mathrm{M})$ was determined by Annexin V staining analysis (E) and Terminal deoxynucleotidyl transferase dUTP nick end labeling (TUNEL) assay (F). This result is representative data of at least three independent experiments. (G) Western blotting analysis of proteins related to cell cycle arrest and apoptosis for $48 \mathrm{~h}$ after treatment of telmisartan $(40 \mu \mathrm{M}) . \beta$-actin was used for a gel-loading control. 


\section{Discussion}

It has been reported that IL13R $\alpha 2$ was overexpressed in various cancers, such as glioblastoma, metastatic colorectal cancer, and ovarian cancer, which suggests that IL13R $\alpha 2$ can play crucial roles in the development of various cancer types [25,26]. A recent study revealed that IL13R $\alpha 2$ might be an important therapeutic target in a perineural invasion, the invasion of cancer to nerves [27]. In another study, IL13R $\alpha 2$ was closely related to cancer cell migration, which indicated that IL13R $\alpha 2$ might be a key factor in metastasis in cancers [28]. It was reported that IL13R $\alpha 2$ was a functional receptor-mediating-signaling pathway in human pancreatic cancer cell lines [29]. They showed that IL13 induced the activation of transforming growth factor- $\beta$ (TGF $\beta$ ) through the AP-1 pathway, which can promote tumorigenesis caused by immunosuppression. In another study using the mouse model, it was demonstrated that two kinds of humanized scFv based chimeric antigen receptor (CAR) T cells targeting IL13R $\alpha 2$ inhibited tumor growth in vitro and in vivo [30]. Sunitinib is an agent for treating metastatic or unresectable clear cell RCC, and IL13R $\alpha 2$ can be a potential target to overcome sunitinib resistance [31]. However, the exact mechanism related to IL13R $\alpha 2$ has not been investigated in RCC development. As shown in Figures 1 and 2, immunohistochemical expression of IL13R $\alpha 2$ was highly associated with cancer-specific survival and relapse-free survival by univariate and multivariate analysis in 229 RCC patients. In addition, the oncogenic role of IL13R $\alpha 2$ was confirmed by the in vitro cell assay. Knock-down of IL13R $\alpha 2$ showed the antiproliferative activity in A498, ACHN, Caki1, and Caki2 cells (Figure 3). As shown in Figure 3G, the expression of pJAK2 was significantly downregulated by transfection of IL13R $\alpha 2$ with siRNA in RCC cells. Mechanistically, IL13R $\alpha 2$ seemed to interact with JAK2 in RCC cells to activate the phosphorylation of JAK2, which may downregulate FOXO3, a representative tumor-suppressive transcriptional factor. To the best of our knowledge, this is the first research to demonstrate the IL13R $\alpha 2 / J A K 2 / F O X O 3$-signaling pathway in cancer development.

Atopic dermatitis $(\mathrm{AD})$ has been the most common type of chronic inflammatory skin disease [32]. JAK2 inhibitors have been identified as effective reagents for the treatment of atopic dermatitis [33]. A recent study showed that JTE-052, which is a novel JAK inhibitor suppressed skin inflammation and had therapeutic effects on chronic dermatitis in rodent models [34]. Interestingly, the recent clinical report has shown that cream containing ruxolitinib that is JAK1/JAK2 inhibitor alleviated AD symptoms and itch effectively in AD patients [35]. These studies suggested that JAK2 inhibitor could be a promising reagent for developing effective drugs for AD treatment. Furthermore, JAK2 inhibitor has been considered a promising therapeutic reagent for arthritis treatment [36]. A recent study has reported that ferulic acid showed anti-arthritic activity in rats induced arthritis through inhibition of the JAK/STAT pathway [37]. It was also reported that the Ershiwuwei Lvxue pill (ELP) that is Tibetan traditional medicine, reduced collagen-induced arthritis through JAK2/STAT3-signaling pathway inhibition [38]. These studies indicated that JAK2 inhibitor also could be considered an effective reagent for arthritis treatment.

IL-13 has been known as a crucial cytokine in chronic airway inflammation, and it plays an important role in AD pathogenesis [39,40]. Because IL-13 is a pivotal cytokine involved in allergic responses, it is important to find an effective way to alleviate immune responses by inhibiting IL-13 [41]. A recent study demonstrated that inhibition of IL-13 for $\mathrm{AD}$ is a new pathway, which suggested that IL-13 inhibitors could be an effective reagent for AD treatment [42]. It was reported that lebrikizumab is an IL-13 inhibitor that has the potential to treat moderate-to-severe AD with fewer side effects [43]. A clinical report showed that tralokinumab is the other IL-13 inhibitor that shows promising results of alleviating moderate-to-severe AD in adult patients. In short, these results supported that IL-13 inhibitor appears to have the potential to be a promising reagent for the development of new drugs for $\mathrm{AD}$ treatment.

Janus kinases, often referred as JAK, have been known as cytoplasmic tyrosine kinase combined with intracellular domains of various cytokine receptors [44]. JAK family member is divided into JAK1, JAK2, JAK3, and TYK2 [45]. According to recent studies, 
JAK2/STAT3 signaling pathway played critical roles in metastasis and progression of cancers, which implied that JAK2 might be a crucial therapeutic target for treatment of cancer [46-49]. Recent study showed that salidroside had anti-cancer effects and suppressed RCC proliferation through inhibition of JAK2/STAT3 signaling pathway [50]. The data presented in this study indicated that salidroside decreased the levels of phosphorylated STAT3 and JAK2 in A498 and 786-0 RCC cells. It was also reported that thymoquinone, a natural compound extracted from black seed oil, possessed anti-cancer effects in RCC cells [51]. According to them, inhibition of JAK2/STAT3 signaling pathway was observed after treatment of thymoquinone in Caki2 cells. Furthermore, recent studies have reported that the synthetic JAK2 inhibitor was considered as the therapeutic agent for other cancer types [52-54]. It was reported that treatment of JAK inhibitors CEP-33779 and NVP-BSK805 helped vincristine work effectively by sensitizing drug-resistant KBV20C oral cancer cells [55]. AG490, JAK2 inhibitor, also inhibited the proliferation and invasion of gallbladder cancer cells through inhibition of JAK2/STAT3 signaling pathway [54]. Thus, our current study supported that JAK2 has a potential to be an important target for various cancer treatment.

Telmisartan is angiotensin II receptor blocker and selectively inhibits the binding of angiotensin II into AT1 receptor [56]. Telmisartan was approved by FDA in 1998 and it has been used to treat high blood pressure and heart failure [57-59]. It also has been reported that telmisartan has anti-cancer effect against several cancer cell lines [60-62]. Recent study showed that telmisartan has cytotoxic effect through generation of reactive oxygen species (ROS) and upregulation of death receptor 5 (DR5) in human lung cancer A549 cells [63]. It was reported that telmisartan inhibited cancer cell growth and induced DNA damage in HHUA human endometrial cancer cells [64]. In another study, telmisartan downregulated Bcl-2 and induced apoptosis in 786-0 RCC cells [65]. Also, recent study has shown that telmisartan exhibited anti-cancer effect in MKN74 gastric cancer cells in vitro and in vivo [66]. Interestingly, this study showed that telmisartan inhibited tumor growth through cell cycle arrest in a mouse xenograft model of gastric cancer. Furthermore, growth inhibitory effect of telmisartan was observed in esophageal squamous cell carcinoma xenograft mouse model [67]. Similar with the previous studies, we observed that telmisartan treatment suppressed cell proliferation and induced cell cycle arrest and apoptosis via inhibition of JAK2 in human RCC cells. However, we still need to perform in vivo experiments using RCC mouse model to prove the anti-cancer activity of telmisartan. We selected telmisartan as one of the strongest JAK2 inhibitors from 821 FDA approved drugs. Since we adopted the screening way based on the assay to measure ATP consumption by JAK2, we thought that telmisartan might compete with ATP to bind the ATP binding site in JAK2. We are planning to conduct the competitive enzyme assay and simulate in silico docking model to prove this hypothesis. As shown in Figure 5G, interestingly, telmisartan treatment caused the downregulation of IL13R $\alpha 2$. It seems that inhibition of JAK2 by telmisartan might induce the transcriptional downregulation of IL13R $\alpha 2$ through inhibition of the phosphorylation of STAT3 transcriptional factor. So, we plan to perform other experiments demonstrating that STAT3 bind to the promoter region of IL13R $\alpha 2$ and whether the binding affinity of STAT3 on the promoter region was weakened by JAK2 inhibition or not.

Since telmisartan has been used to treat heart disease for 22 years, there are lots of previous reports for researcher to examine the possible working mechanism of telmisartan in terms of anti-cancer activity. The relationship between JAK2 and angiotensin II signaling pathway has been investigated in various studies [68-71]. It has been reported that angiotensin II activates STAT3 through the IL6/gp130/JAK2 signaling pathway in cardiomyocytes [72]. AG490, well-known JAK2 inhibitor, inhibited angiotensin IIinduced differentiation of bone marrow-derived mesenchymal stem cells (BM-MSCs) into keratinocytes, which suggested that JAK2 is associated with angiotensin II signaling pathway [73]. Recent study has shown that angiotensin II upregulated nitroxidative stress via JAK2/STAT3 signaling pathway leading to the hyperproliferation of vascular smooth mus- 
cle cells (VSMCs) [74]. In another study, it is demonstrated that inhibition of angiotensin II through JAK2/STAT3 signaling pathway suppressed tubular epithelial myofibroblast trans-differentiation mediated by hepatocyte growth factor (HGF) [75]. Thus, we thought that blocking of angiotensin II binding into AT1 receptor by telmisartan might cause the inhibition of JAK2 through direct or indirect signaling pathway in RCC cells. We might need to investigate the change of the phosphorylation status of JAK2 under knock-down of AT1 receptor in RCC cells. Peroxisome proliferator-activated receptor $\gamma(\operatorname{PPAR} \gamma)$ is also well-known agonistic target of telmisartan. PPAR $\gamma$ is a member of nuclear receptor family and it plays an important role in regulating lipid metabolism [76]. According to a previous research, activation of JAK2/STAT3 signaling pathway was associated with downregulation of PPAR $\gamma$, which promoted fibrosis in rats [77]. Furthermore, PPAR $\gamma$ decreased the protein expression of suppressor of cytokine signaling 3 (SOCS3) through inhibition of JAK2/STAT3 signaling pathway leading to alleviation of hepatocyte steatosis [78]. Additionally, it was reported that pioglitazone, one of PPAR $\gamma$ agonists, inhibited breast cancer growth by regulating JAK2/STAT signaling pathway in vitro and in vivo [79]. For the further study, we are trying to examine that rosiglitazone, FDA approved hypoglycemic agent as PPAR $\gamma$ agonists, has anti-cancer activity against RCC through inhibition of JAK2 phosphorylation.

In this study, we demonstrated the clinicopathologically significance of IL13R $\alpha 2$, a kind of the independent receptor for IL13, in RCC progression. Mechanistically, downregulation of IL13R $\alpha 2$ in RCC cells seemed to decrease the phosphorylation of JAK2 and increase expression of FOXO3, suggesting that IL13R $\alpha 2$ probably is involved in the progression of RCC through JAK2/FOXO3 pathway (Figure 6). In addition, we screened an FDA approved drug library to identify the novel candidates inhibiting JAK2 in RCC cells and selected telmisartan as the one of strongest JAK2 inhibitors. Telmisartan displayed the anti-proliferative activity in RCC cells, which could be one of the therapeutic options for RCC patients.

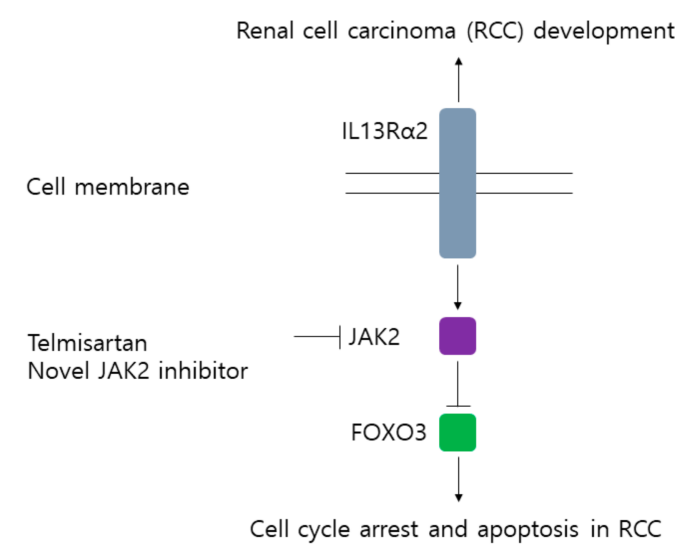

Figure 6. A diagram for the possible oncogenic role of IL13R $\alpha 2$ in renal cell carcinoma (RCC) by activation of JAK2 and inhibition of FOXO3.

Supplementary Materials: The following are available online at https: / www.mdpi.com/article / 10.3390/jpm11040284/s1, Figure S1: (A). The correlation pattern between expression of IL13R $\alpha 2$, pJAK2, JAK2, and FOXO3 in A498, ACHN, Caki1, and Caki2 cells. Western blotting analysis of IL13R $\alpha 2$, pJAK2, JAK2, and FOXO3 in each cell line. $\beta$-actin was used for a gel-loading control; (B) Reduction of ATP consumption by telmisartan in a dose-dependent manner in vitro. JAK2 protein was incubated with the indicated concentration of AZD1480 or telmisartan, peptide substrate, and ATP for $30 \mathrm{~min}$ at $37^{\circ} \mathrm{C}$. After incubation, the reaction mixture was incubated with Glo-Max solution for $30 \mathrm{~min}$ at room temperature to stop the reaction. Then, the remaining ATP level in each reaction was measured by a microplate reader for luminescence; $(C)$. Reduction of phosphorylation of JAK2 by telmisartan. Western blotting analysis of pJAK2 and JAK2 after telmisartan treatment $(0$, $10,20$, and $40 \mu \mathrm{M}) . \beta$-actin was used for a gel-loading control. 
Author Contributions: Conceptualization, M.-A.K., J.L., C.M.L., H.S.P., K.Y.J., and S.-H.P.; methodology, M.-A.K., J.L., C.M.L., H.S.P., K.Y.J., and S.-H.P.; software, M.-A.K., J.L., C.M.L., H.S.P., K.Y.J., and S.-H.P.; validation, M.-A.K., J.L., C.M.L., H.S.P., K.Y.J., and S.-H.P.; formal analysis, M.-A.K., J.L., C.M.L., H.S.P., K.Y.J., and S.-H.P.; investigation, M.-A.K., J.L., C.M.L., H.S.P., K.Y.J., and S.-H.P.; resources, M.-A.K., J.L., C.M.L., H.S.P., K.Y.J., and S.-H.P.; data curation, M.-A.K., J.L., C.M.L., H.S.P., K.Y.J., and S.-H.P.; writing—original draft preparation, M.-A.K., J.L., C.M.L., H.S.P., K.Y.J., and S.-H.P.; writing—review and editing, M.-A.K., J.L., C.M.L., H.S.P., K.Y.J., and S.-H.P.; visualization, M.-A.K., J.L., C.M.L., H.S.P., K.Y.J., and S.-H.P.; supervision, K.Y.J. and S.-H.P.; project administration, K.Y.J. and S.-H.P.; funding acquisition, K.Y.J. and S.-H.P. All authors have read and agreed to the published version of the manuscript.

Funding: This research was supported by the Basic Science Research Program (NRF-2014R1A6A3A04054307) through the National Research Foundation of Korea (NRF), funded by the Ministry of Science and ICT (MSIP). This research was supported by the Medical Research Center Program (NRF2017R1A5A2015061) through the National Research Foundation of Korea (NRF), funded by the Ministry of Science and ICT (MSIP).

Institutional Review Board Statement: The study was conducted according to the guidelines of the Declaration of Helsinki, and approved by the Institutional Review Board of Jeonbuk National University Hospital (IRB number: CUH 2019-11-039, date of approval: 10 November 2019).

Informed Consent Statement: The IRB approval (CUH 2019-11-039) contained a waiver for written informed consent based on the retrospective and anonymous character of the study.

Data Availability Statement: The datasets used in the current study are available from the corresponding author upon reasonable request.

Conflicts of Interest: The authors declare no conflict of interest.

\section{References}

1. Ferlay, J.; Soerjomataram, I.; Dikshit, R.; Eser, S.; Mathers, C.; Rebelo, M.; Parkin, D.M.; Forman, D.; Bray, F. Cancer incidence and mortality worldwide: Sources, methods and major patterns in GLOBOCAN 2012. Int. J. Cancer 2014, 136, E359-E386. [CrossRef] [PubMed]

2. Fisher, R.; Gore, M.; Larkin, J. Current and future systemic treatments for renal cell carcinoma. Semin. Cancer Biol. 2013, 23, 38-45. [CrossRef] [PubMed]

3. Escudier, B.; Eisen, T.; Stadler, W.M.; Szczylik, C.; Oudard, S.; Siebels, M.; Negrier, S.; Chevreau, C.; Solska, E.; Desai, A.A.; et al. Sorafenib in Advanced Clear-Cell Renal-Cell Carcinoma. N. Engl. J. Med. 2007, 356, 125-134. [CrossRef] [PubMed]

4. Choueiri, T.K.; Motzer, R.J. Systemic Therapy for Metastatic Renal-Cell Carcinoma. N. Engl. J. Med. 2017, 376, 354-366. [CrossRef]

5. Heng, D.Y.; Xie, W.; Regan, M.M.; Warren, M.A.; Golshayan, A.R.; Sahi, C.; Eigl, B.J.; Ruether, J.D.; Cheng, T.; North, S.; et al. Prognostic Factors for Overall Survival in Patients With Metastatic Renal Cell Carcinoma Treated With Vascular Endothelial Growth Factor-Targeted Agents: Results From a Large, Multicenter Study. J. Clin. Oncol. 2009, 27, 5794-5799. [CrossRef]

6. Heng, D.Y.; Xie, W.; Regan, M.M.; Harshman, L.C.; Bjarnason, G.; Vaishampayan, U.N.; Mackenzie, M.; Wood, L.; Donskov, F.; Tan, M.-H.; et al. External validation and comparison with other models of the International Metastatic Renal-Cell Carcinoma Database Consortium prognostic model: A population-based study. Lancet Oncol. 2013, 14, 141-148. [CrossRef]

7. Hsieh, J.J.; Purdue, M.P.; Signoretti, S.; Swanton, C.; Albiges, L.; Schmidinger, M.; Heng, D.Y.; Larkin, J.; Ficarra, V. Renal cell carcinoma. Nat. Rev. Dis. Prim. 2017, 3, 1-19. [CrossRef]

8. Qi, W.-X.; Huang, Y.-J.; Yao, Y.; Shen, Z.; Min, D.-L. Incidence and Risk of Treatment-Related Mortality with mTOR Inhibitors Everolimus and Temsirolimus in Cancer Patients: A Meta-Analysis. PLoS ONE 2013, 8, e65166. [CrossRef]

9. Escudier, B.; Szczylik, C.; Porta, C.; Gore, M. Treatment selection in metastatic renal cell carcinoma: Expert consensus. Nat. Rev. Clin. Oncol. 2012, 9, 327-337. [CrossRef]

10. Hershey, G.K. IL-13 receptors and signaling pathways: An evolving web. J. Allergy Clin. Immunol. 2003, 111, 677-690. [CrossRef]

11. Bhardwaj, R.; Suzuki, A.; Leland, P.; Joshi, B.H.; Puri, R.K. Identification of a novel role of IL-13R $\alpha 2$ in human Glioblastoma multiforme: Interleukin-13 mediates signal transduction through AP-1 pathway. J. Transl. Med. 2018, 16, 1-13. [CrossRef]

12. Okamoto, H.; Yoshimatsu, Y.; Tomizawa, T.; Kunita, A.; Takayama, R.; Morikawa, T.; Komura, D.; Takahashi, K.; Oshima, T.; Sato, M.; et al. Interleukin-13 receptor $\alpha 2$ is a novel marker and potential therapeutic target for human melanoma. Sci. Rep. 2019, 9, 1-13. [CrossRef]

13. Bartolomé, R.A.; Jaén, M.; Casal, J.I. An IL13R $\alpha 2$ peptide exhibits therapeutic activity against metastatic colorectal cancer. Br. J. Cancer 2018, 119, 940-949. [CrossRef]

14. Papageorgis, P.; Ozturk, S.; Lambert, A.W.; Neophytou, C.M.; Tzatsos, A.; Wong, C.K.; Thiagalingam, S.; Constantinou, A.I. Targeting IL13Ralpha2 activates STAT6-TP63 pathway to suppress breast cancer lung metastasis. Breast Cancer Res. 2015, 17, 98. [CrossRef] 
15. Park, S.-H.; Chung, Y.M.; Ma, J.; Yang, Q.; Berek, J.S.; Hu, M.C.-T. Pharmacological activation of FOXO3 suppresses triple-negative breast cancer in vitro and in vivo. Oncotarget 2016, 7, 42110-42125. [CrossRef]

16. Tang, M.; Hu, X.; Wang, Y.; Yao, X.; Zhang, W.; Yu, C.; Cheng, F.; Li, J.; Fang, Q. Ivermectin, a potential anticancer drug derived from an antiparasitic drug. Pharmacol. Res. 2021, 163, 105207. [CrossRef]

17. Borém, L.M.A.; Neto, J.F.R.; Brandi, I.V.; Lelis, D.F.; Santos, S.H.S. The role of the angiotensin II type I receptor blocker telmisartan in the treatment of non-alcoholic fatty liver disease: A brief review. Hypertens. Res. 2018, 41, 394-405. [CrossRef]

18. Moch, H.; Humphrey, P.A.; Ulbright, T.M. WHO Classification of Tumours of the Urinary System and Male Genital Organs, 4th ed.; World Health Organization: Geneva, Switzerland, 2016; Volume 70, pp. 93-105.

19. Amin, M.B.; American Joint Committee on Cancer; American Cancer Society. AJCC Cancer Staging Manual; Springer: Chicago, IL, USA, 2017; 1024p, p. xvii.

20. Allred, D.C.; Harvey, J.M.; Berardo, M.; Clark, G.M. Prognostic and predictive factors in breast cancer by immunohistochemical analysis. Mod. Pathol. 1998, 11, 155-168.

21. Kang, M.-A.; Lee, J.; Ha, S.H.; Lee, C.M.; Kim, K.M.; Jang, K.Y.; Park, S.-H. Interleukin4R $\alpha$ (IL4R $\alpha$ ) and IL13R $\alpha 1$ Are Associated with the Progress of Renal Cell Carcinoma through Janus Kinase 2 (JAK2)/Forkhead Box O3 (FOXO3) Pathways. Cancers 2019, 11, 1394. [CrossRef]

22. Kim, K.M.; Hussein, U.K.; Park, S.-H.; Kang, M.A.; Moon, Y.J.; Zhang, Z.; Song, Y.; Park, H.S.; Bae, J.S.; Park, B.-H.; et al. FAM83H is involved in stabilization of $\beta$-catenin and progression of osteosarcomas. J. Exp. Clin. Cancer Res. 2019, 38, 1-15. [CrossRef]

23. Park, H.J.; Bae, J.S.; Kim, K.M.; Moon, Y.J.; Park, S.-H.; Ha, S.H.; Hussein, U.K.; Zhang, Z.; Park, H.S.; Park, B.-H.; et al. The PARP inhibitor olaparib potentiates the effect of the DNA damaging agent doxorubicin in osteosarcoma. J. Exp. Clin. Cancer Res. 2018, 37, 107. [CrossRef] [PubMed]

24. Kim, K.M.; Hussein, U.K.; Bae, J.S.; Park, S.-H.; Kwon, K.S.; Ha, S.H.; Park, H.S.; Lee, H.; Chung, M.J.; Moon, W.S.; et al. The Expression Patterns of FAM83H and PANX2 Are Associated with Shorter Survival of Clear Cell Renal Cell Carcinoma Patients. Front. Oncol. 2019, 9, 14. [CrossRef] [PubMed]

25. Sai, K.K.S.; Sattiraju, A.; Almaguel, F.G.; Xuan, A.; Rideout, S.; Krishnaswamy, R.S.; Zhang, J.; Herpai, D.M.; Debinski, W.; Mintz, A. Peptide-based PET imaging of the tumor restricted IL13RA2 biomarker. Oncotarget 2017, 8, 50997-51007. [CrossRef] [PubMed]

26. Bartolomé, R.A.; Martín-Regalado, Á.; Jaén, M.; Zannikou, M.; Zhang, P.; Ríos, V.D.L.; Balyasnikova, I.V.; Casal, J.I. Protein Tyrosine Phosphatase-1B Inhibition Disrupts IL13R $\alpha 2$-Promoted Invasion and Metastasis in Cancer Cells. Cancers 2020, 12, 500. [CrossRef]

27. Fujisawa, T.; Shimamura, T.; Goto, K.; Nakagawa, R.; Muroyama, R.; Ino, Y.; Horiuchi, H.; Endo, I.; Maeda, S.; Harihara, Y.; et al. A Novel Role of Interleukin 13 Receptor alpha2 in Perineural Invasion and its Association with Poor Prognosis of Patients with Pancreatic Ductal Adenocarcinoma. Cancers 2020, 12, 1294. [CrossRef]

28. Chong, S.T.; Tan, K.M.; Kok, C.Y.L.; Guan, S.P.; Lai, S.H.; Lim, C.; Hu, J.; Sturgis, C.; Eng, C.; Lam, P.Y.P.; et al. IL13RA2 Is Differentially Regulated in Papillary Thyroid Carcinoma vs Follicular Thyroid Carcinoma. J. Clin. Endocrinol. Metab. 2019, 104, 5573-5584. [CrossRef]

29. Shimamura, T.; Fujisawa, T.; Husain, S.R.; Joshi, B.H.; Puri, R.K. Interleukin 13 Mediates Signal Transduction through Interleukin 13 Receptor $\alpha 2$ in Pancreatic Ductal Adenocarcinoma: Role of IL-13 Pseudomonas Exotoxin in Pancreatic Cancer Therapy. Clin. Cancer Res. 2010, 16, 577-586. [CrossRef]

30. Yin, Y.; Boesteanu, A.C.; Binder, Z.A.; Xu, C.; Reid, R.A.; Rodriguez, J.L.; Cook, D.R.; Thokala, R.; Blouch, K.; McGettigan-Croce, B.; et al. Checkpoint Blockade Reverses Anergy in IL-13R $\alpha 2$ Humanized scFv-Based CAR T Cells to Treat Murine and Canine Gliomas. Mol. Ther. Oncolytics 2018, 11, 20-38. [CrossRef]

31. Shibasaki, N.; Yamasaki, T.; Kanno, T.; Arakaki, R.; Sakamoto, H.; Utsunomiya, N.; Inoue, T.; Tsuruyama, T.; Nakamura, E.; Ogawa, O.; et al. Role of IL13RA2 in Sunitinib Resistance in Clear Cell Renal Cell Carcinoma. PLoS ONE 2015, 10, e0130980. [CrossRef]

32. Rodrigues, M.A.; Torres, T. JAK/STAT inhibitors for the treatment of atopic dermatitis. J. Dermatol. Treat. 2019, 31, 33-40. [CrossRef]

33. Cotter, D.G.; Schairer, D.; Eichenfield, L. Emerging therapies for atopic dermatitis: JAK inhibitors. J. Am. Acad. Dermatol. 2018, 78, S53-S62. [CrossRef]

34. Tanimoto, A.; Shinozaki, Y.; Yamamoto, Y.; Katsuda, Y.; Taniai-Riya, E.; Toyoda, K.; Kakimoto, K.; Kimoto, Y.; Amano, W.; Konishi, N.; et al. A novel JAK inhibitor JTE-052 reduces skin inflammation and ameliorates chronic dermatitis in rodent models: Comparison with conventional therapeutic agents. Exp. Dermatol. 2017, 27, 22-29. [CrossRef]

35. Kim, B.S.; Howell, M.D.; Sun, K.; Papp, K.; Nasir, A.; Kuligowski, M.E. Treatment of atopic dermatitis with ruxolitinib cream (JAK1/JAK2 inhibitor) or triamcinolone cream. J. Allergy Clin. Immunol. 2020, 145, 572-582. [CrossRef]

36. Malemud, C.J. The role of the JAK/STAT signal pathway in rheumatoid arthritis. Ther. Adv. Musculoskelet. Dis. 2018, 10, 117-127. [CrossRef]

37. Zhu, L.; Zhang, Z.; Xia, N.; Zhang, W.; Wei, Y.; Huang, J.; Ren, Z.; Meng, F.; Yang, L. Anti-arthritic activity of ferulic acid in complete Freund's adjuvant (CFA)-induced arthritis in rats: JAK2 inhibition. Inflammopharmacology 2019, 28, 463-473. [CrossRef]

38. Liu, C.; Zhao, Q.; Zhong, L.; Li, Q.; Li, R.; Li, S.; Li, Y.; Li, N.; Su, J.; Dhondrup, W.; et al. Tibetan medicine Ershiwuwei Lvxue Pill attenuates collagen-induced arthritis via inhibition of JAK2/STAT3 signaling pathway. J. Ethnopharmacol. 2021, $270,113820$. [CrossRef] 
39. Wollenberg, A.; Howell, M.D.; Guttman-Yassky, E.; Silverberg, J.I.; Kell, C.; Ranade, K.; Moate, R.; van der Merwe, R. Treatment of atopic dermatitis with tralokinumab, an anti-IL-13 mAb. J. Allergy Clin. Immunol. 2019, 143, 135-141. [CrossRef]

40. Marone, G.; Granata, F.; Pucino, V.; Pecoraro, A.; Heffler, E.; Loffredo, S.; Scadding, G.W.; Varricchi, G. The Intriguing Role of Interleukin 13 in the Pathophysiology of Asthma. Front. Pharmacol. 2019, 10, 1387. [CrossRef]

41. Bieber, T. Interleukin-13: Targeting an underestimated cytokine in atopic dermatitis. Allergy 2020, 75, 54-62. [CrossRef]

42. Ratnarajah, K.; Le, M.; Muntyanu, A.; Mathieu, S.; Nigen, S.; Litvinov, I.V.; Jack, C.S.; Netchiporouk, E. Inhibition of IL-13: A New Pathway for Atopic Dermatitis. J. Cutan. Med. Surg. 2020, 10, 1203475420982553. [CrossRef]

43. Loh, T.Y.; Hsiao, J.L.; Shi, V.Y. Therapeutic Potential of Lebrikizumab in the Treatment of Atopic Dermatitis. J. Asthma Allergy 2020, 13, 109-114. [CrossRef]

44. Clark, J.D.; Flanagan, M.E.; Telliez, J.-B. Discovery and Development of Janus Kinase (JAK) Inhibitors for Inflammatory Diseases. J. Med. Chem. 2014, 57, 5023-5038. [CrossRef]

45. Roskoski, R. Janus kinase (JAK) inhibitors in the treatment of inflammatory and neoplastic diseases. Pharmacol. Res. 2016, 111, 784-803. [CrossRef]

46. Yuan, K.; Ye, J.; Liu, Z.; Ren, Y.; He, W.; Xu, J.; He, Y.; Yuan, Y. Complement C3 overexpression activates JAK2/STAT3 pathway and correlates with gastric cancer progression. J. Exp. Clin. Cancer Res. 2020, 39, 1-15. [CrossRef]

47. Zeng, Y.-T.; Liu, X.-F.; Yang, W.-T.; Zheng, P.-S. REX1 promotes EMT-induced cell metastasis by activating the JAK2/STAT3signaling pathway by targeting SOCS1 in cervical cancer. Oncogene 2019, 38, 6940-6957. [CrossRef]

48. Liu, K.; Gao, H.; Wang, Q.; Wang, L.; Zhang, B.; Han, Z.; Chen, X.; Han, M.; Gao, M. Retracted: Hispidulin suppresses cell growth and metastasis by targeting PIM 1 through JAK 2/ STAT 3 signaling in colorectal cancer. Cancer Sci. 2018, 109, 1369-1381. [CrossRef]

49. Zhou, X.; Yan, T.; Huang, C.; Xu, Z.; Wang, L.; Jiang, E.; Wang, H.; Chen, Y.; Liu, K.; Shao, Z.; et al. Melanoma cell-secreted exosomal miR-155-5p induce proangiogenic switch of cancer-associated fibroblasts via SOCS1/JAK2/STAT3 signaling pathway. J. Exp. Clin. Cancer Res. 2018, 37, 1-15. [CrossRef]

50. Lv, C.; Huang, Y.; Liu, Z.-X.; Yu, D.; Bai, Z.-M. Salidroside reduces renal cell carcinoma proliferation by inhibiting JAK2/STAT3 signaling. Cancer Biomark. 2016, 17, 41-47. [CrossRef]

51. Chae, I.G.; Chun, K.-S. Abstract 4844: Thymoquinone induces apoptosis through inhibition of JAK2/STAT3 signaling via production of ROS in human renal cancer Caki cells. Cancer Chem. 2016, 76, 4844. [CrossRef]

52. Morgan, E.L.; Macdonald, A. JAK2 Inhibition Impairs Proliferation and Sensitises Cervical Cancer Cells to Cisplatin-Induced Cell Death. Cancers 2019, 11, 1934. [CrossRef]

53. Kim, J.W.; Gautam, J.; Kim, J.; Kang, K.W. Inhibition of tumor growth and angiogenesis of tamoxifen-resistant breast cancer cells by ruxolitinib, a selective JAK2 inhibitor. Oncol. Lett. 2019, 17, 3981-3989. [CrossRef] [PubMed]

54. Fu, L.X.; Lian, Q.W.; Pan, J.D.; Xu, Z.L.; Zhou, T.M.; Ye, B. JAK2 tyrosine kinase inhibitor AG490 suppresses cell growth and invasion of gallbladder cancer cells via inhibition of JAK2/STAT3 signaling. J. Boil. Regul. Homeost. Agents 2017, 31, 51-58.

55. Cheon, J.H.; Kim, K.S.; Yadav, D.K.; Kim, M.; Kim, H.S.; Yoon, S. The JAK2 inhibitors CEP-33779 and NVP-BSK805 have high P-gp inhibitory activity and sensitize drug-resistant cancer cells to vincristine. Biochem. Biophys. Res. Commun. 2017, 490, 1176-1182. [CrossRef] [PubMed]

56. McClellan, K.J.; Markham, A. Telmisartan. Drugs 1998, 56, 1039-1044. [CrossRef]

57. Sharpe, M.; Jarvis, B.; Goa, K.L. Telmisartan. Drugs 2001, 61, 1501-1529. [CrossRef]

58. Sukumaran, V.; Veeraveedu, P.T.; Gurusamy, N.; Yamaguchi, K.; Lakshmanan, A.P.; Ma, M.; Suzuki, K.; Kodama, M.; Watanabe, K. Cardioprotective Effects of Telmisartan against Heart Failure in Rats Induced By Experimental Autoimmune Myocarditis through the Modulation of Angiotensin-Converting Enzyme-2/Angiotensin 1-7/Mas Receptor Axis. Int. J. Biol. Sci. 2011, 7, 1077-1092. [CrossRef]

59. McFarlane, S. Telmisartan and cardioprotection. Vasc. Heal. Risk Manag. 2011, 7, 677-683. [CrossRef]

60. Lee, L.D.; Mafura, B.; Lauscher, J.C.; Seeliger, H.; Kreis, M.E.; Gröne, J. Antiproliferative and apoptotic effects of telmisartan in human colon cancer cells. Oncol. Lett. 2014, 8, 2681-2686. [CrossRef]

61. Matsuyama, M.; Funao, K.; Kuratsukuri, K.; Tanaka, T.; Kawahito, Y.; Sano, H.; Chargui, J.; Touraine, J.-L.; Yoshimura, N.; Yoshimura, R. Telmisartan inhibits human urological cancer cell growth through early apoptosis. Exp. Ther. Med. 2010, 1, 301-306. [CrossRef]

62. Wu, T.T.-L.; Niu, H.-S.; Chen, L.-J.; Cheng, J.-T.; Tong, Y.-C. Increase of human prostate cancer cell (DU145) apoptosis by telmisartan through PPAR-delta pathway. Eur. J. Pharmacol. 2016, 775, 35-42. [CrossRef]

63. Rasheduzzaman, M.; Moon, J.-H.; Lee, J.-H.; Nazim, U.M.; Park, S.-Y. Telmisartan generates ROS-dependent upregulation of death receptor 5 to sensitize TRAIL in lung cancer via inhibition of autophagy flux. Int. J. Biochem. Cell Biol. 2018, 102, 20-30. [CrossRef]

64. Koyama, N.; Nishida, Y.; Ishii, T.; Yoshida, T.; Furukawa, Y.; Narahara, H. Telmisartan Induces Growth Inhibition, DNA DoubleStrand Breaks and Apoptosis in Human Endometrial Cancer Cells. PLoS ONE 2014, 9, e93050. [CrossRef] [PubMed]

65. Júnior, R.F.D.A.; Oliveira, A.L.C.L.; Silveira, R.F.D.M.; Rocha, H.A.D.O.; Cavalcanti, P.D.F.; De Araújo, A.A. Telmisartan induces apoptosis and regulates Bcl-2 in human renal cancer cells. Exp. Biol. Med. 2014, 240, 34-44. [CrossRef] 
66. Fujita, N.; Fujita, K.; Iwama, H.; Kobara, H.; Fujihara, S.; Chiyo, T.; Namima, D.; Yamana, H.; Kono, T.; Takuma, K.; et al. Antihypertensive drug telmisartan suppresses the proliferation of gastric cancer cells in vitro and in vivo. Oncol. Rep. 2020, 44, 339-348. [CrossRef]

67. Matsui, T.; Chiyo, T.; Kobara, H.; Fujihara, S.; Fujita, K.; Namima, D.; Nakahara, M.; Kobayashi, N.; Nishiyama, N.; Yachida, T.; et al. Telmisartan Inhibits Cell Proliferation and Tumor Growth of Esophageal Squamous Cell Carcinoma by Inducing S-Phase Arrest In Vitro and In Vivo. Int. J. Mol. Sci. 2019, 20, 3197. [CrossRef]

68. Marrero, M.B.; Venema, V.J.; Ju, H.; Eaton, D.C.; Venema, R.C. Regulation of angiotensin II-induced JAK2 tyrosine phosphorylation: Roles of SHP-1 and SHP-2. Am. J. Physiol. Content 1998, 275, C1216-C1223. [CrossRef]

69. McWhinney, C.D.; Dostal, D.; Baker, K. Angiotensin II Activates Stat5 Through Jak2 Kinase in Cardiac Myocytes. J. Mol. Cell. Cardiol. 1998, 30, 751-761. [CrossRef]

70. Shaw, S.S.; Schmidt, A.M.; Banes, A.K.; Wang, X.; Stern, D.M.; Marrero, M.B. S100B-RAGE-Mediated Augmentation of Angiotensin II-Induced Activation of JAK2 in Vascular Smooth Muscle Cells Is Dependent on PLD2. Diabetes 2003, 52, 2381-2388. [CrossRef]

71. Banes-Berceli, A.K.L.; Ketsawatsomkron, P.; Ogbi, S.; Patel, B.; Pollock, D.M.; Marrero, M.B. Angiotensin II and endothelin-1 augment the vascular complications of diabetes via JAK2 activation. Am. J. Physiol. Circ. Physiol. 2007, 293, H1291-H1299. [CrossRef]

72. Han, J.; Ye, S.; Zou, C.; Chen, T.; Wang, J.; Li, J.; Jiang, L.; Xu, J.; Huang, W.; Wang, Y.; et al. Angiotensin II Causes Biphasic STAT3 Activation Through TLR4 to Initiate Cardiac Remodeling. Hypertension 2018, 72, 1301-1311. [CrossRef]

73. Jiang, X.; Wu, F.; Xu, Y.; Yan, J.-X.; Wu, Y.-D.; Li, S.-H.; Liao, X.; Liang, J.-X.; Li, Z.-H.; Liu, H.-W. A novel role of angiotensin II in epidermal cell lineage determination: Angiotensin II promotes the differentiation of mesenchymal stem cells into keratinocytes through the p38 MAPK, JNK and JAK2 signalling pathways. Exp. Dermatol. 2019, 28, 59-65. [CrossRef] [PubMed]

74. Hossain, E.; Li, Y.; Anand-Srivastava, M.B. Role of JAK2/STAT3 pathway in angiotensin II-induced enhanced expression of Gi $\alpha$ proteins and hyperproliferation of aortic vascular smooth muscle cells. Can. J. Physiol. Pharmacol. 2021, 99, 237-246. [CrossRef] [PubMed]

75. Wang, H.-Y.; Zhang, C.; Xiao, Q.-F.; Dou, H.; Chen, Y.; Gu, C.-M.; Cui, M.-J. Hepatocyte growth factor inhibits tubular epithelialmyofibroblast transdifferentiation by suppression of angiotensin II via the JAK2/STAT3 signaling pathway. Mol. Med. Rep. 2017, 15, 2737-2743. [CrossRef] [PubMed]

76. Harris, S.G.; Phipps, R.P. The nuclear receptor PPAR gamma is expressed by mouse T lymphocytes and PPAR gamma agonists induce apoptosis. Eur. J. Immunol. 2001, 31, 1098-1105. [CrossRef]

77. Mahmoud, A.M.; Desouky, E.M.; Hozayen, W.G.; Bin-Jumah, M.; El-Nahass, E.-S.; Soliman, H.A.; Farghali, A.A. Mesoporous Silica Nanoparticles Trigger Liver and Kidney Injury and Fibrosis Via Altering TLR4/NF-kB, JAK2/STAT3 and Nrf2/HO-1 Signaling in Rats. Biomolecules 2019, 9, 528. [CrossRef]

78. Bi, J.; Sun, K.; Wu, H.; Chen, X.; Tang, H.; Mao, J. PPAR $\gamma$ alleviated hepatocyte steatosis through reducing SOCS3 by inhibiting JAK2/STAT3 pathway. Biochem. Biophys. Res. Commun. 2018, 498, 1037-1044. [CrossRef]

79. Jiao, X.X.; Lin, S.Y.; Lian, S.X.; Qiu, Y.R.; Li, Z.H.; Chen, Z.H.; Lu, W.Q.; Zhang, Y.; Deng, L.; Jiang, Y.; et al. Inhibition of the breast cancer by PPAR $\gamma$ agonist pioglitazone through JAK2/STAT3 pathway. Neoplasma 2020, 67, 834-842. [CrossRef] 